\title{
Knowledge Sharing in \\ Cooperative Research and Development
}

\author{
Mariko Sakakibara
}

Working Paper No. 156

This paper was presented as part of a workshop, The Changing Japanese Firm, Dec. 11-12, 1998 at Columbia University. The workshop was sponsored by the Center on Japanese Economy and

Business, Columbia Business School, with additional financial support from The Jerome A. Chazen Institute of International Business, Columbia Business School and the Center for International Business Education, Columbia University.

\author{
Working Paper Series \\ Center on Japanese Economy and Business \\ Columbia Business School \\ January 1999
}




\title{
Knowledge Sharing in Cooperative Research and Development
}

\author{
Mariko Sakakibara \\ Anderson Graduate School of Management \\ University of California, Los Angeles
}

September 9, 1998

Correspondence to: Mariko Sakakibara, Anderson Graduate School of Management, University of California, Los Angeles, 110 Westwood Plaza, B508, Los Angeles, CA 90095-1481, USA. Tel.: +1-310-825-7831; fax: +1-310-206-3337; e-mail: mariko.sakakibara@anderson.ucla.edu.

Some of the ideas and data presented in this article are the product of an ongoing collaborative research effort (or knowledge sharing) with Lee Branstetter. I would like to thank James Bohn, Richard Caves, Wesley Cohen, Glenn Ellison, Drew Fudenberg, Stephen Hansen, Chiaki Hara, Marvin Lieberman, Michael Porter, Michael Whinston and seminar participants at Harvard and UCLA for helpful suggestions on earlier versions of this paper. Aya Chacar, Rajesh Chakrabarti, Makoto Nakayama, Kaoru Nabeshima and Heather Berry provided valuable research assistance. Financial support from the Harvard Business School Division of Research and the Center for International Business Education and Research at the UCLA Anderson Graduate School of Management is gratefully acknowledged. This research was partly conducted when the author was a Special Researcher at the National Institute of Science and Technology Policy, Science and Technology Agency, Japan. Any remaining errors are my own. 


\begin{abstract}
This article examines the effects of knowledge sharing or endogenous spillovers among R\&D consortia participants on $R \& D$ competition when $R \& D$ enhances a firm's absorptive capacity. A game-theoretic model illustrates how different compositions of R\&D consortia affect spillovers and R\&D spending of participants. When a firm participates in a consortium whose members are from diverse industries, the model suggests that this participation increases spillover rates among participants and intensifies firms' $\mathrm{R} \& \mathrm{D}$ efforts to learn from other members in the consortium. An econometric analysis based on the panel data of 267 Japanese firms over 13 years shows evidence of this learning effect.
\end{abstract}

Key words: R\&D consortia, knowledge sharing, learning, absorptive capacity, spillovers JEL Classification: O31, O38, L52 


\section{Introduction}

What are the effects of $R \& D$ cooperation on $R \& D$ efforts by cooperating firms? More specifically, under what circumstances does $R \& D$ cooperation stimulate $R \& D$ competition, reflected in the increase in firms' R\&D spending? The purpose of this article is to evaluate the effect of $R \& D$ cooperation on the R\&D expenditures of participating firms when R\&D enhances a firm's absorptive capacity (which is defined here as a firm's ability to assimilate and exploit knowledge generated by other firms) by developing a game-theoretic model and conducting an empirical analysis of Japanese governmentsponsored R\&D consortia.

The focus of the article is on knowledge sharing or endogenous spillovers among R\&D consortia participants, which are determined by the composition of $R \& D$ consortia. The results of this article suggest that when R\&D consortia consist of firms with diverse technological knowledge, these firms bring knowledge-sharing opportunities, which result in higher spillover rates among participants and more intensified R\&D efforts of participants to learn from other members of the consortia. In contrast, in the case of $R \& D$ consortia which consist of firms with similar technological capabilities, it is found that participating firms are more likely to cut their R\&D expenditures.

Cooperative $R \& D$ has been widely celebrated as a means of promoting private $R \& D$, and some see it as a major tool for enhancing industry competitiveness. ${ }^{1}$ Possible benefits of cooperative R\&D include cost and risk sharing among participants which allow them to execute large-scale projects, and knowledge sharing or learning of skills and capabilities from other participants.

Japan is regarded as a forerunner in the practice of cooperative $R \& D$. The most celebrated example is the VLSI (Very Large Scale Integrated circuit) project, designed to help Japan compete with the U.S. in semiconductor technology. The project, conducted between 1975 and 1985 with a budget of 130 billion yen (US\$591 million), of which $22 \%$ was financed by the government, developed state-of-the-

\footnotetext{
${ }^{1}$ Cooperative R\&D can be executed in many forms, including R\&D contracts, R\&D consortia, and research joint ventures. In this analysis, these forms are collectively referred to as R\&D consortia or cooperative R\&D
} 
art semiconductor manufacturing technology. After the project, Japanese semiconductor companies gained world leadership. While this project is regarded as a success, it is widely believed that it is only one of many successful projects (Okimoto, 1989). The perceived success of VLSI-type projects has motivated governments in other countries to emulate "Japanese style" collaboration. Examples in the U.S. include the 1984 National Cooperative Research Act, and its successor bill (passed in 1993); SEMATECH (Semiconductor Manufacturing Technology) is one cooperative program which was established under these bills in the U.S. In Europe, major efforts include the European Strategic Programme for Research and Development of Information Technology (ESPRIT) project, the UK Alvey project, and programs under the European Research Coordination Agency (EURECA). The Korean government has also launched a series of cooperative $R \& D$ projects.

Despite all of these developments, the impact of cooperative $R \& D$ has been examined empirically by only a few studies and comprehensive research is almost nonexistent. There are many case studies (for example, Katz and Ordover, 1990; Fransman, 1990; Murphy, 1991; Ouchi and Bolton, 1988; Dunning and Robson, 1988), but most treatments have been based on anecdotal evidence, or on the accounts of a few highly publicized cooperative R\&D projects. In particular, the evaluation of the effect of cooperative R\&D on participating firms is examined in only a few studies, including Irwin and Klenow (1996), Link, Teece, and Finan (1996), and Branstetter and Sakakibara (1998). While government support of cooperative R\&D continues, ${ }^{2}$ there is an increased interest in OECD countries in the evaluation of government programs on innovation and technology; this is driven in part by budget stringency and in part by a greater concern for accountability and transparency in government actions (OECD, 1997). More empirical research on this issue is, therefore, warranted.

This article is organized as follows. Section 2 examines the existing literature. Section 3 presents a game-theoretic model which illustrates a learning effect of $R \& D$ consortia. Though this model is

projects, interchangeably.

${ }_{2}^{2}$ The Clinton Administration, for example, has increased the budget of the Advanced Technology Program (ATP) which funds collaborative research of the private sector in the U.S. 
developed with the case of government-sponsored $R \& D$ consortia in mind, it also applies to a broader class of R\&D consortia. Section 4 describes both the econometric specifications and the empirical results. An original data set of government-sponsored R\&D consortia in Japan which includes 237 consortia organized over 34 years is the basis for this analysis. From this data set, a panel data of 267 Japanese firms and their participation in $R \& D$ consortia is drawn and analyzed. The results show that participation in consortia whose members bring diverse technological capabilities increases firms' R\&D spending. Finally, in section 5, implications are drawn from the findings.

\section{Previous Research}

Past theoretical research on cooperative $R \& D$ has focused on three primary motivations for cooperation: sharing of fixed costs among R\&D participants, realizing economies of scale in $R \& D$, and avoiding "wasteful" duplication (Katz, 1986; d'Aspremont and Jacquemin, 1988; Choi, 1990; Katz and Ordover, 1990; Motta, 1992; Suzumura, 1992; Ziss, 1994; Salant and Shaffer, 1998). All three are scale-based motives, and they imply that the principal purpose of cooperative R\&D is to share costs. This literature typically assumes that firms are symmetrical in terms of their capabilities or knowledge, which implies that the cooperating firms belong to a single industry. Firms seek to achieve a single R\&D outcome, and it is implicitly assumed that there is only one efficient way to pursue this outcome. Participating firms, therefore, benefit from this efficient, non-duplicative approach. A basis for these assumptions is the desire to obtain interesting equilibrium outcomes from the game-theoretic models. A result, however, is that this literature only addresses a limited range of cooperative activity.

In contrast, in the managerial literature, firms in alliances are often recognized to possess heterogeneous capabilities, and they may or may not be direct competitors in the product market. The resource-based view suggests that a firm can be conceived as a portfolio of core competencies (Prahalad and Hamel, 1990). Alliances can be viewed as opportunities for one partner to internalize the skills or competencies of the other(s) to create next-generation competencies (Hamel, 1991). Firms possess a 
knowledge base, and this knowledge - particularly technological knowledge - is often "tacit" (Polanyi, 1958) and not easily diffused across the firm's boundaries. An organizational vehicle, such as an alliance, is required to effect this transfer (Kogut, 1988).

These resource-based propositions imply that a key objective of cooperative R\&D is complementary knowledge or skill sharing among participants. Complementary knowledge is defined here as knowledge stocks that, in combination, yield new and improved R\&D results. ${ }^{3}$ This knowledge sharing effect would be greater if participants of $R \& D$ consortia come from different industries, because those participants would bring more complementary knowledge.

There are three ways that the diversity of $R \& D$ consortia participants affects the $R \& D$ expenditures of participating firms. The first is the spillover effect of a firm's own R\&D on others' R\&D productivity. Nelson (1959) and Arrow (1962) argued that the existence of R\&D spillovers makes it difficult for innovators to capture the full social benefits of their innovative activity, which depresses the incentives to conduct R\&D. Through $R \& D$ cooperation, firms internalize the externality created through spillovers, thus restoring the incentive for firms to conduct R\&D (Spence, 1984). If the original level of spillover is low, and if cooperation in R\&D increases spillover rates among consortia participants, everything else being equal, cooperation tends to increase R\&D expenditures by consortia participants (Katz, 1986). The intuition behind this result is that when the spillovers from $R \& D$ consortia to non-participants are low, and when intensive $R \& D$ sharing within the consortia increases the effectiveness of $R \& D$, consortia participants are encouraged to conduct more $R \& D$. It is typically assumed that the level of spillover is larger within the industry in which the technology originates ("home" industry) than between "home" and "distant" industries (Griliches, 1992). It is therefore possible that a firm could encounter higher spillovers in an R\&D consortia with diverse members than it normally would from other consortia members (from diverse industries) without

\footnotetext{
${ }^{3}$ Examples of such skill sharing include the combination of optics and electronics, which led optoelectronics and the development of fiber-optics communication systems, and the fusing of mechanical and electronics technologies
} 
consortia activity; this could result in an increase in the firm's R\&D spending. Additionally, Levin and Reiss (1988) showed that when own and rival R\&D are imperfect substitutes, an increase in spillover productivity, which is the extent of the usefulness of knowledge possessed by other firms, causes a firm's R\&D intensity to rise. If $R \& D$ consortia participants are from diverse industries, it is more likely that firms have worked on different technological areas and possess different expertise which can be complementary to each other's R\&D; this could also result in an increase in a firm's R\&D spending.

The second effect of cooperative R\&D on the firm's R\&D spending is from learning, which is defined here as efforts by firms to assimilate and exploit knowledge or information generated by other firms. Learning affects the intra-consortium spillover level. The sharing of complementary knowledge implies that learning from other participants and from cooperative R\&D results is important. Cohen and Levinthal (1989) showed that a high spillover rate in R\&D among competitors can provide a positive incentive to conduct $R \& D$ when a company's own $R \& D$ increases its learning capability. Cooperative R\&D is a "forced" spillover scheme. The implication is that the spillover rate among consortia participants is likely much higher than would exist without the consortia, with participants increasing their R\&D efforts in order to learn from others. Levin et al. (1987) point out that independent in-house $\mathrm{R} \& \mathrm{D}$ is the most effective means to learn about rivals' technology. It is also documented that Japanese companies participating in consortia customarily set up in-house research groups to absorb and utilize the results of R\&D consortia (Kodama, 1985). This learning effect is likely to be large for firms which come from diverse industries. ${ }^{4}$

The third effect relates to the impact of R\&D cooperation on product market competition. Katz (1986) argues that if a higher level of R\&D makes market competition more intense by lowering firms' marginal cost of production, then the resulting decline in profits will reduce their incentive to conduct

producing the mechatronics revolution, which has transformed the machine tool industry (Kodama, 1992).

${ }^{4}$ In the long run, firms which participate in $R \& D$ consortia will increase their capabilities to learn from others over time, and as a result, firms' R\&D spending for learning purposes might decrease. Also, product market competition among R\&D consortia participants with diverse capabilities might intensify, because learning among participants might make their capabilities similar. In this sense, this article is focused on the short-run effect. 
R\&D. Katz showed that $R \& D$ consortia can depress $R \& D$ as firms seek to lessen the severity of competition in the product market. Katz' argument applies to the case of R\&D consortia whose participants come from a single industry, where expected market competition will be intensified by the outcome of cooperative R\&D. Participants in R\&D consortia who come from diverse industries, however, are not necessarily direct rivals in the product market. This market competition effect is, therefore, expected to be smaller in this case. Even when participants from different industries enter the target product market of the $R \& D$ project, these firms possess heterogeneous capabilities, likely with products and strategies highly differentiated, with the result that the expected degree of ex-post competition will be lower than when consortia participants hold more homogeneous capabilities.

All three effects suggest the possibility that R\&D consortia whose members are from diverse industries may increase participants' $R \& D$ spending, relative to consortia of single-industry participants. ${ }^{5}$ Among three effects, the learning effect of R\&D consortia has not been formalized in the theoretical literature. In the following section, we present a model of the learning effect that builds upon Cohen and Levinthal (1989).

\section{Model}

\subsection{Model Structure}

We model an $R \& D$ consortium in which firms share $R \& D$ outcomes at a jointly determined rate. We compare this case to three others, including one case with no cooperation and two cases with broader cooperation. In this model, two firms invest in process R\&D, which can reduce marginal production cost, denoted c. Firms decide individual R\&D investment, M, as well as the degree to which they want to

\footnotetext{
${ }^{5}$ One might argue that an increase in R\&D efficiency by the formation of R\&D consortia will affect firms differently depending on the composition of R\&D consortia. Single-industry consortia can achieve increased efficiency through economies of scale and avoidance of wasteful duplications, while consortia participants from diverse industries might find efficiencies in the easier acquisition of necessary complementary resources for R\&D. In both cases, it is uncertain if this cost-reducing effect of R\&D consortia increases firm R\&D spending or not. This depends on whether the "income" effect or the "substitution" effect dominates. It is also uncertain how this cost-reducing effect differs by the composition of R\&D consortia.
} 
share their knowledge with other firms, denoted $\theta$, and defined in detail later ${ }^{6}$. After R\&D is conducted, each firm decides what quantity to produce, denoted $\mathrm{q}$, and the firms engage in product market competition with homogeneous goods. ${ }^{7}$

We assume cost-reducing $R \& D$, in which the marginal production cost of firm $i$ is given as

$$
c^{i}=c^{i}\left(z^{i}\right)
$$

where $\mathrm{z}^{\mathrm{i}}$ is firm i's stock of knowledge, and it is assumed $\mathrm{c}_{\mathrm{zi}}^{\mathrm{i}}<0$ and $\mathrm{c}_{\text {zizi }}^{\mathrm{i}}>0$. Also it is assumed $\mathrm{c}(0)$ is positive and finite, and $c_{z i}^{i}$ is always finite. Following Spence (1984), if one thinks of the product as the services it delivers to the customer, and $R \& D$ reduces the cost of delivering services, this cost-reducing $R \& D$ can be interpreted as product-innovation $R \& D$.

R\&D investment in this model reduces production cost by increasing the stock of knowledge held by firms, as proposed by Cohen and Levinthal (1989). We assume firm i's stock of knowledge $\mathrm{z}^{\mathrm{i}}$ increases the firm's gross earnings (i.e. earnings from sales) through cost reduction, $\Pi^{\mathrm{i}}\left(\mathrm{z}^{\mathrm{i}}, \mathrm{z}^{\mathrm{j}}\right)\left(\mathrm{i} . \mathrm{e} ., \Pi_{\mathrm{zi}}^{\mathrm{i}}>\right.$ 0 ), but at a diminishing rate (i.e., $\Pi_{z i z i}^{\mathrm{i}}<0$ ). Further, $\mathrm{z}^{\mathrm{i}}$ is a function of

$$
z^{i}=z^{i}\left(M^{i}, M^{j}, \theta^{i}, \beta\right)
$$

where $M^{i}$ is a firm's own investment in $R \& D ; M^{j}$ is the other firm's $R \& D$ investment; $\theta^{j}$ is the degree the other firm wants to share the knowledge with this firm, and thus, represents the firm's knowledge sharing rate or the spillover rate; and the parameter $\beta$ is the degree of knowledge complementarity or technological distance in this model. The functional form of $z^{i}$ is the following,

$$
\mathbf{z}^{\mathrm{i}}=\mathbf{M}^{\mathrm{i}}+\gamma^{\mathrm{i}}\left(\mathbf{M}^{\mathrm{i}}, \beta\right) \theta^{\mathrm{j}} \mathbf{M}^{\mathrm{j}}
$$

where $\gamma^{\mathrm{i}}$ is the fraction of competitor's knowledge that the firm is able to assimilate and exploit, and thus

\footnotetext{
${ }^{6}$ The case of endogenous spillover has not been fully examined in the theory literature. There are some attempts, including Kamien et al. (1992), Vonortas (1994), and Poyago-Theotoky (1995), to model various degrees of R\&D cooperation, though they assume that some fixed sharing rate is automatically achieved among participants.

${ }^{7}$ Steurs (1995) analyzed a case of inter-industry R\&D cooperation as well as intra-industry R\&D cooperation, and assumed that an exogenous inter-industry spillover rate is different from an intra-industry spillover rate. $\mathrm{He}$ also assumes that firms in different industries compete in different markets. Here we assume that, even if firms come from different industries, they compete in the same product market. This reflects the case when firms from different industries try to enter a new market by taking different approaches and using different capabilities.
} 
represents the firm's learning capability or absorptive capacity. It is assumed $0 \leq \gamma \leq 1$ and $0 \leq \theta \leq 1$. Therefore, firm j's R\&D investment contributes to firm i's own knowledge stock, though its effect does not exceed the effect of firm i's own R\&D. It is assumed there is no overlap in firm $i$ and $j$ 's research, and so research investments by both firms additively contribute to each firm's stock of knowledge, reflecting a case in which firms possess different expertise. In other words, firms are horizontally differentiated in terms of their knowledge.

A firm's learning capability, $\gamma^{\mathrm{i}}$, depends on two factors. One is its own $\mathrm{R} \& \mathrm{D}$ effort, $\mathrm{M}^{\mathrm{i}}$, and the other is the complementarity of its knowledge with that of other firms, denoted as $\beta$. Knowledge complementarity $\beta$ is defined here as the distance between or the degree of difference in knowledge firms possess. $\beta$ can also be interpreted as the proximity of the firms in technology space, in the manner suggested by Jaffe (1986). We assume an R\&D consortium which consists of participants from a single industry has a very small $\beta$, while an $R \& D$ consortium which consists of participants from different industries has a large $\beta .^{8}$ Further, it is assumed $0 \leq \beta \leq 1$. We also assume that the firm's own R\&D increases its own learning capability, $\gamma_{M}>0$, though at a constant or decreasing rate, $\gamma_{M M} \leq 0$. The more complementary or more distant the other firm's knowledge becomes, the more difficult is it for the firm to learn (i.e., $\gamma_{\beta}\left(\mathbf{M}^{\mathrm{i}}, \beta\right)<0$ ), because firms do not possess the basic knowledge to understand a distant technology easily. However, the larger is $\beta$, the larger is the marginal impact of own R\&D on learning capability such that $\gamma_{\mathrm{M} \beta}\left(\mathrm{M}^{\mathrm{i}}, \beta\right)>0$, because the contribution of more complementary knowledge to its learning is greater than more similar knowledge once it is learned. Therefore, it is assumed that increasing $\beta$ increases the marginal effect of $R \& D$ on learning capability, but diminishes the level of learning capability. ${ }^{9}$ Also, when $\beta$ approaches zero, learning capability is less responsive to the level of

\footnotetext{
${ }^{8}$ We assume $\beta$ is exogenously determined by the characteristics of knowledge participants already possess. One can argue that $\beta$ might change over time, or might change during cooperation. $\beta$ can also be interpreted as a Bayesian conjecture of knowledge complementarity, therefore it is appropriate to assume $\beta$ takes the same value throughout the period considered here.

${ }^{9}$ One might argue that the effect of $\beta$ on learning might be nonlinear, i.e. if $\beta$ becomes very large, the
} 
own R\&D and $\gamma^{\mathrm{i}}$ approaches 1 . We also assume the value of $\gamma_{M}$ and $\gamma_{M M}$ is always finite.

It is assumed there is a cost for knowledge sharing, denoted as $s(\theta)$, for each firm, which reflects opportunity costs for a firm such as costs to assign good researchers to transmit its knowledge to the other firm, or costs to keep its own R\&D secret from the other firm. It is therefore assumed that $s(0)=\infty$, $s^{\prime}(0)=-\infty, \quad s(1)=\infty, s^{\prime}(1)=\infty, s^{\prime \prime}(\theta)>0$. This assumption means both complete secrecy and full knowledge sharing are extremely costly, because full knowledge sharing requires education of the researchers from other firms, while complete secrecy requires the setup of R\&D facilities in an isolated location and tight information control to and from the research facility. ${ }^{10}$ The construction of the stock of knowledge implies that two conditions are necessary to benefit from R\&D by the other firm: the supplying firm is willing to share its knowledge, and the receiving firm has to undertake its own R\&D to learn effectively from the other firm.

We also assume that an increase in the other firm's knowledge level decreases firm i's gross profit and firm i's marginal benefit from increasing its own knowledge level so that $\Pi_{z j}^{\mathrm{i}}<0$, and $\Pi_{\text {zizj }}^{\mathrm{i}}<0$, where $z^{j}$ represents a competitor's knowledge level. We assume the effect of a firm's own knowledge level on its gross profit is greater than the effect of the knowledge level of the opponent, which implies $\left|\Pi_{\mathrm{zi}}^{\mathrm{i}}\right|>\left|\Pi_{\mathrm{zj}}^{\mathrm{i}}\right|$. In addition to this assumption, we assume $\Pi_{\mathrm{zi}}^{\mathrm{i}}>1$ always holds, which means gross profit increases from this R\&D investment are always larger than the increase in the stock of knowledge.

Two three-stage games are considered first. At stage one, firms decide $\theta^{1}$ and $\theta^{2}$, the knowledge sharing rate. At stage two, firms decide $\mathrm{M}^{1}$ and $\mathrm{M}^{2}$, the amount of $\mathrm{R} \& \mathrm{D}$ effort. At stage three the firms engage in the product market where Cournot competition is assumed. We consider two cases at stage one. The first is a non-cooperative case, in which $\theta^{1}$ and $\theta^{2}$ are determined independently. The second is

contribution of very distant knowledge to a firm's learning becomes negative. Here we assume that the condition $\gamma_{\mathrm{M} \beta}\left(\mathbf{M}^{\mathrm{i}}, \beta\right)>0$ holds for any $\beta$ both in a model and an empirical analysis because we assume a feasible design of $R \& D$ consortia precludes the case of an R\&D consortium which consists of firms with such different capabilities that participants cannot learn each other.

${ }^{10}$ This assumption is made to solve the model, but it reflects the real situation of firms in that the economic costs of complete secrecy or full sharing are surely higher than the costs of intermediate cases. 
a cooperative $\theta$ case or an $R \& D$ consortium case, in which firms pick the same $\theta$ jointly. We seek a subgame perfect Nash equilibrium. We only seek symmetric equilibria; the same $\theta$ is chosen as a Nash equilibrium in a non-cooperative case, and both firms are restricted to the same $\theta$ in the cooperative case. $^{11}$

$\theta$, determined at stage one, can reflect the number and quality of researchers a firm is willing to dedicate to exchange knowledge, or the frequency of meetings among firms, therefore we assume $\theta$ is observable. Cooperatively determined $\theta$ means there exists some mutual enforcement mechanism to maintain the same $\theta$, or cooperative commitment. ${ }^{12}$ It can be interpreted that, in this model, $R \& D$ is conducted separately in the research labs of companies, and each company makes decisions in order to maximize its own profit.

Firms face an inverse demand function $\mathrm{D}^{-1}(\mathrm{Q})$, where $\mathrm{Q}=\mathrm{q}^{1}+\mathrm{q}^{2}$ is the total quantity produced. Here $\mathrm{D}^{-1}$ is assumed to be linear, so that

$$
D^{-1}=a-b\left(q^{1}+q^{2}\right)
$$

where $\mathrm{q}^{1}, \mathrm{q}^{2}$ are the quantities each firm produces, and $\mathrm{a}>>0, \mathrm{~b}>0$.

After these two cases, the third case is examined in which $\theta$ and $M$ are cooperatively determined. Finally, a collusive case is examined in which all the decision variables are cooperatively determined.

\subsection{Analysis}

\subsubsection{Non-cooperative case}

In a non-cooperative case, firms choose $\theta, \mathbf{M}$, and $\mathrm{q}$ independently. Employing the usual backward induction, firm i's problem at stage three, given $\theta^{i}, \theta^{j}, \mathbf{M}^{i}, \mathbf{M}^{\mathrm{j}}, \beta, \mathbf{q}^{\mathrm{j}}$, becomes

$$
\operatorname{Max}_{q^{i}} \mathrm{f}^{\mathrm{i}}=\mathrm{q}^{\mathrm{i}}\left(\mathrm{D}^{-1}-\mathrm{c}^{\mathrm{i}}\right)-\mathrm{M}^{\mathrm{i}}-\mathrm{s}\left(\theta^{\mathrm{i}}\right)
$$

\footnotetext{
${ }^{11}$ One might argue that there would be asymmetric equilibria even if firms are symmetric. One justification for this assumption is that in a consortium it would be more mutually acceptable and "implementable" for firms to simply choose the same $\theta$.

${ }^{12}$ One interpretation is that, if the government is involved in the formation of an R\&D consortium, it can enforce a certain level of $\theta$ for both parties, because the government can observe the number and quality of the researchers in an $R \& D$ consortium through their résumé or publications, or the number of meetings among consortia participants.
} 


$$
=q^{i}\left(c^{i}\left(z^{i}\right)\right)\left[a-b\left\{q^{i}\left(c^{i}\left(z^{i}\right)\right)+q^{j}\left(c^{j}\left(z^{j}\right)\right)\right\}-c^{i}\left(z^{i}\right)\right]-M^{i}-s\left(\theta^{i}\right)
$$

where $\mathbf{M}^{\mathrm{i}}=\mathbf{M}^{\mathrm{i}}\left(\theta^{\mathrm{i}}, \theta^{\mathrm{j}}, \beta\right), \mathbf{z}^{\mathrm{i}}=\mathbf{M}^{\mathrm{i}}\left(\theta^{\mathrm{i}}, \theta^{\mathrm{j}}, \beta\right)+\gamma^{\mathrm{i}}\left(\mathbf{M}^{\mathrm{i}}, \beta\right) \theta^{\mathrm{j}} \mathbf{M}^{\mathrm{j}}\left(\theta^{\mathrm{i}}, \theta^{\mathrm{j}}, \beta\right)$.

Its solution is a Cournot Nash equilibrium, which is given as

$$
q^{i *}=\frac{1}{3 b}\left(a-2 c^{i}+c^{j}\right) \quad \mathrm{i}=1,2
$$

By substituting $\mathrm{q}^{\mathrm{i}}, \mathrm{q}^{\mathrm{j}}$ in $(1)$ to $\mathrm{q}^{\mathrm{i} *}\left(\mathrm{c}^{\mathrm{i}}, \mathrm{c}^{\mathrm{j}}\right), \mathrm{q}^{\mathrm{j}^{*}}\left(\mathrm{c}^{\mathrm{i}}, \mathrm{c}^{\mathrm{j}}\right)$, the gross profit function $\Pi^{\mathrm{i}}=\frac{1}{9 b}\left\{\mathrm{a}-2 \mathrm{c}^{\mathrm{i}}\left(\mathrm{z}^{\mathrm{i}}\right)\right.$ $\left.+\mathrm{c}^{\mathrm{j}}\left(\mathrm{z}^{\mathrm{j}}\right)\right\}^{2}$ is obtained. In order for the assumptions of the derivatives of $\Pi, \Pi_{\mathrm{zizi}}^{\mathrm{i}}<0$ and $\Pi_{\mathrm{zi}}^{\mathrm{i}}>1$ to hold, we make the following assumptions on the cost function and parameters of the demand function;

$$
\begin{aligned}
& \Pi_{z i z i}^{i}=-\frac{4}{9 b}\left\{\left(a-2 c^{i}+c^{j}\right) \frac{\partial^{2} c^{i}}{\partial z^{i 2}}-2\left(\frac{\partial c^{i}}{\partial z^{i}}\right)^{2}\right\}<0 \\
& \Pi_{z i}^{i}=-\frac{4}{9 b}\left(a-2 c^{i}+c^{j}\right) \frac{\partial c^{i}}{\partial z^{i}}>1
\end{aligned}
$$

A numerical example confirms an exponential cost function $c=e^{-z}$ satisfies these assumptions with properly determined $a$ and $b$.

At stage two, firm i picks $M^{i}$ to maximize its profit, given $q^{i^{*}}\left(c^{i}, c^{j}\right), q^{j^{*}}\left(c^{i}, c^{j}\right), \theta^{i}, \theta^{j}, \beta, M^{j} . \quad$ By substituting $q^{i}, q^{j}$ in $(1)$ to $q^{i^{*}}\left(c^{i}, c^{j}\right), q^{j^{*}}\left(c^{i}, c^{j}\right)$, firm i's problem is:

$$
\begin{aligned}
& \underset{M^{i}}{\operatorname{Max}} g^{i}=\frac{1}{9 b}\left\{\mathrm{a}-2 \mathrm{c}^{\mathrm{i}}\left(\mathrm{z}^{\mathrm{i}}\right)+\mathrm{c}^{\mathrm{j}}\left(\mathrm{z}^{\mathrm{j}}\right)\right\}^{2}-\mathbf{M}^{\mathrm{i}}-\mathrm{s}\left(\theta^{\mathrm{i}}\right) \\
& \quad \text { where } \mathbf{M}^{\mathrm{i}}=\mathbf{M}^{\mathrm{i}}\left(\theta^{\mathrm{i}}, \theta^{\mathrm{j}}, \beta\right), \mathrm{z}^{\mathrm{i}}=\mathbf{M}^{\mathrm{i}}\left(\theta^{\mathrm{i}}, \theta^{\mathrm{j}}, \beta\right)+\gamma^{\mathrm{i}}\left(\mathbf{M}^{\mathrm{i}}, \beta\right) \theta^{\mathrm{j}} \mathbf{M}^{\mathrm{j}}\left(\theta^{\mathrm{i}}, \theta^{\mathrm{j}}, \beta\right) .
\end{aligned}
$$

Note $\Pi^{\mathrm{i}}=\frac{1}{9 b}\left\{\mathrm{a}-2 \mathrm{c}^{\mathrm{i}}\left(\mathrm{z}^{\mathrm{i}}\right)+\mathrm{c}^{\mathrm{j}}\left(\mathrm{z}^{\mathrm{j}}\right)\right\}^{2}=\frac{1}{9 b}\left\{\mathrm{a}-2 \mathrm{c}^{\mathrm{i}}\left(\mathbf{M}^{\mathrm{i}}+\gamma^{\mathrm{i}}\left(\mathbf{M}^{\mathrm{j}}, \beta\right) \theta^{\mathrm{i}} \mathbf{M}^{\mathrm{j}}\right)+\mathrm{c}^{\mathrm{j}}\left(\mathbf{M}^{\mathrm{j}}+\gamma^{\mathrm{j}}\left(\mathbf{M}^{\mathrm{j}}, \beta\right) \theta^{\mathrm{i}} \mathbf{M}^{\mathrm{i}}\right)\right\}^{2}$, and the firstorder condition by firm i becomes

$$
\frac{\partial g^{i}}{\partial M^{i}}=\Pi_{z i}^{i} \frac{d z^{i}}{d M^{i}}+\Pi_{z j}^{i} \frac{d z^{j}}{d M^{i}}-1
$$




$$
=\Pi_{z \mathrm{i}}^{\mathrm{i}}\left(1+\gamma_{\mathrm{Mi}_{\mathrm{i}}}^{\mathrm{i}} \theta^{\mathrm{j}} \mathrm{M}^{\mathrm{j}}\right)+\Pi_{\mathrm{zj}}^{\mathrm{i}} \gamma^{\mathrm{j}} \theta^{\mathrm{i}}-1=0
$$

Equation (4) implicitly defines firm i's reaction function $\mathbf{M}^{\mathrm{i}^{*}}\left(\mathrm{M}^{\mathrm{j}}\right)$ which gives the profit maximizing level of $\mathbf{M}^{\mathrm{i}}$ for any given $\mathbf{M}^{\mathrm{j}}$. Nash equilibrium at stage two $\left[\mathrm{M}^{\mathrm{iNC}}\left(\theta^{\mathrm{i}}, \theta^{\mathrm{j}}, \beta\right), \mathbf{M}^{\mathrm{jNC} C^{*}}\left(\theta^{\mathrm{i}}, \theta^{\mathrm{j}}, \beta\right)\right]$ is given at the intersection of the two reaction functions $\mathbf{M}^{\mathrm{i}^{*}}\left(\mathrm{M}^{\mathrm{j}}\right)$ and $\mathrm{M}^{\mathrm{j}^{*}}\left(\mathrm{M}^{\mathrm{i}}\right)$, derived from (4) for both firms. The Nash equilibrium is assumed to be stable. ${ }^{14}$

At stage one, $\theta^{1}$ and $\theta^{2}$ are chosen independently. Firm i solves

$$
\begin{aligned}
\operatorname{Max}_{\theta^{i}} \mathrm{~h}^{\mathrm{i}}=\frac{1}{9 b}\left\{\mathrm{a}-2 \mathrm{c}^{\mathrm{i}}\left(\mathrm{z}^{\mathrm{i}}\right)+\mathrm{c}^{\mathrm{j}}\left(\mathrm{z}^{\mathrm{j}}\right)\right\}^{2}-\mathrm{M}^{\mathrm{iNC} C^{*}}\left(\theta^{\mathrm{i}}, \theta^{\mathrm{j}}, \beta\right)-\mathrm{s}\left(\theta^{\mathrm{i}}\right) \\
\quad \text { where } \mathrm{z}^{\mathrm{i}}=\mathbf{M}^{\mathrm{iNC} \mathrm{C}^{*}}\left(\theta^{\mathrm{i}}, \theta^{\mathrm{j}}, \beta\right)+\gamma^{\mathrm{i}}\left(\mathbf{M}^{\mathrm{iNC}}\left(\theta^{\mathrm{i}}, \theta^{\mathrm{j}}, \beta\right), \beta\right) \theta^{\mathrm{j}} \mathbf{M}^{\mathrm{jNC}}\left(\theta^{\mathrm{i}}, \theta^{\mathrm{j}}, \beta\right) .
\end{aligned}
$$

The first-order condition for a Nash equilibrium by firm i becomes

$$
\begin{aligned}
\frac{\partial h^{i}}{\partial \theta^{i}}= & \Pi_{z i}^{i} \frac{d z^{i}}{d \theta^{i}}+\Pi_{z j}^{i} \frac{d z^{j}}{d \theta^{i}}-\frac{\partial M^{i^{*}}}{\partial \theta^{i}}-s^{\prime}\left(\theta^{i}\right) \\
= & \Pi_{z i}^{i}\left\{\frac{\partial M^{i^{*}}}{\partial \theta^{i}}+\theta^{j}\left(\gamma_{M i}^{i} \frac{\partial M^{i^{*}}}{\partial \theta^{i}} M^{j^{*}}+\gamma^{i} \frac{\partial M^{j^{*}}}{\partial \theta^{i}}\right)\right\} \\
& +\Pi_{z j}^{i}\left\{\frac{\partial M^{j^{*}}}{\partial \theta^{i}}+\gamma^{j} M^{i^{*}}+\theta^{i}\left(\gamma_{M j}^{j} \frac{\partial M^{j^{*}}}{\partial \theta^{i}} M^{i^{*}}+\gamma^{j} \frac{\partial M^{i^{*}}}{\partial \theta^{i}}\right)\right\}-\frac{\partial M^{i^{*}}}{\partial \theta^{i}}-s^{\prime}\left(\theta^{i}\right)=0 \mathrm{i}=1,2
\end{aligned}
$$

It can be easily shown that there is at least one solution $\theta^{i *}$ which satisfies the first-order condition for any $\theta^{j}$ and $\beta$. Reaction functions for both firms are defined from first-order conditions. A Nash equilibrium in knowledge sharing $\left[\theta^{\mathrm{iNC}}(\beta), \theta^{\mathrm{jNC}}(\beta)\right]$ is given at the intersection of the reaction functions

\footnotetext{
${ }^{13}$ The second-order condition for firm i becomes

$$
\begin{aligned}
& \frac{\partial^{2} g^{i}}{\partial M^{i 2}}=\Pi_{z i}^{i} \gamma_{M i M i}^{i} \theta^{j} M^{j}+\left\{\Pi_{z i z i}^{i}\left(1+\gamma_{M i}^{i} \theta^{j} M^{j}\right)+\Pi_{z i z j}^{i} \gamma^{j} \theta^{i}\right\}\left(1+\gamma_{M i}^{i} \theta^{j} M^{j}\right) \\
& +\gamma^{\mathrm{j}} \theta^{\mathrm{i}}\left\{\Pi_{\text {zizj }}^{\mathrm{i}}\left(1+\gamma_{\mathrm{Mi}}^{\mathrm{i}} \theta^{\mathrm{j}} \mathrm{M}^{\mathrm{j}}\right)+\Pi_{\text {zjjj }}^{\mathrm{i}}{ }^{\mathrm{j}} \theta^{\mathrm{i}}\right\} \quad \mathrm{i}=1,2
\end{aligned}
$$

The first-order effect of $\mathrm{z}$ on profit, $\Pi_{\mathrm{z}}^{\mathrm{i}} \mathrm{\gamma}_{\mathrm{MiMi}}^{\mathrm{i}} \theta^{\mathrm{i}} \mathbf{M}^{\mathrm{j}}$, is zero or negative. Among second-order effects, the term $\left\{\Pi_{z i z i}^{i}\left(1+\gamma_{M i}^{i} \theta^{j} M^{j}\right)+\Pi_{z i z j}^{i} \theta^{j}\right\}\left(1+\gamma_{M i}^{i} \theta^{j} M^{j}\right)$ is always negative, while the sign of $\gamma^{j} \theta^{i}\left\{\Pi_{z i z j}^{i}\left(1+\gamma_{M i}^{i} \theta^{j} M^{j}\right)+\Pi_{z i z j}^{i} j^{j} \theta^{i}\right\}$ depends on the sign and magnitude of $\Pi_{z \mathrm{z} z \mathrm{j}}^{\mathrm{i}}$. The impact of the former term is always larger than the latter term, since $\gamma^{j} \theta^{i} \leq 1$. Therefore the second order condition is always satisfied.

${ }^{14} \frac{\partial^{2} g^{i}}{\partial M^{i 2}} \frac{\partial^{2} g^{j}}{\partial M^{j 2}}-\frac{\partial^{2} g^{i}}{\partial M^{i} \partial M^{j}} \frac{\partial^{2} g^{j}}{\partial M^{i} \partial M^{j}}>0$ 
$\theta^{i^{*}}\left(\theta^{j}\right)$ and $\theta^{j^{*}}\left(\theta^{i}\right)$. The Nash equilibrium is assumed to be stable. ${ }^{15}$

Substituting Nash equilibrium values of $\theta^{\mathrm{iNC}}(\beta)$ and $\theta^{\mathrm{iNC} C^{*}}(\beta)$ into (6) gives the noncooperative equilibrium profit as a function of knowledge complementarity $\beta$.

$$
\mathrm{h}^{\mathrm{i}}(\beta)=\mathrm{h}^{\mathrm{i}}\left(\theta^{\mathrm{iNC}}(\beta), \theta^{\mathrm{jNC}}(\beta), \beta\right)
$$

At a symmetric equilibrium $\theta^{\mathrm{iNC}}(\beta)=\theta^{\mathrm{jNC}}(\beta)=\theta^{\mathrm{NC}^{*}}(\beta)$, and $\mathrm{M}^{\mathrm{iNC}}(\beta)=\mathrm{M}^{\mathrm{jNC}}(\beta)=\mathrm{M}^{\mathrm{NC}}(\beta)$.

\subsubsection{Cooperative $\theta$ case $--\mathrm{R} \& \mathrm{D}$ consortium case}

In the second game, firms choose $\mathrm{q}$ and $\mathrm{M}$ independently, but choose the same knowledge sharing rate $\theta$ jointly. This case is intended to model the situation in which the formation of R\&D consortia is allowed but firms cannot cooperatively determine their R\&D outlays because of antitrust considerations.

Nash equilibrium at stage three is the same as in the non-cooperative case. At stage two, the first-order condition is the same as the previous case except that $\theta^{i}=\theta^{j}=\theta$,

$$
\frac{\partial^{i}}{\partial M^{i}}=\Pi_{z \mathrm{i}}^{\mathrm{i}}\left(1+\gamma_{M i}^{\mathrm{i}} \theta M^{\mathrm{j}}\right)+\Pi_{\mathrm{zj}}^{\mathrm{i}} \gamma^{\mathrm{j} \theta}-1=0 \quad \mathrm{i}=1,2
$$

By symmetry, the Nash equilibrium becomes $\mathrm{M}^{\mathrm{iC} *}(\theta, \beta)=\mathbf{M}^{\mathrm{j} \mathrm{C}^{*}}(\theta, \beta)=\mathbf{M}^{\mathrm{C}^{*}}(\theta, \beta)$. Also, $\gamma^{\mathrm{i} \mathrm{C}^{*}}=\gamma^{\mathrm{j} \mathrm{C}^{*}}=\gamma^{\mathrm{C}^{*}}$ $=\gamma\left(\mathbf{M}^{\mathrm{C}^{*}}, \beta\right)$.

At stage one, firm i solves

$$
\begin{aligned}
\underset{\theta}{\operatorname{Max}} \mathrm{k}^{\mathrm{i}} & =\frac{1}{9 b}\left\{\mathrm{a}-2 \mathrm{c}^{\mathrm{i}}\left(\mathrm{z}^{\mathrm{i}}\right)+\mathrm{c}^{\mathrm{j}}\left(\mathrm{z}^{\mathrm{j}}\right)\right\}^{2}-\mathrm{M}^{\mathrm{i} \mathrm{C}^{*}}(\theta, \beta)-\mathrm{s}(\theta) \\
& \text { where } \mathrm{z}^{\mathrm{i}}=\mathrm{M}^{\mathrm{i} \mathrm{C}^{*}}(\theta, \beta)+\gamma^{\mathrm{i}}\left(\mathrm{M}^{\mathrm{i} \mathrm{C}^{*}}(\theta, \beta), \beta\right) \theta^{\mathrm{j}} \mathrm{M}^{\mathrm{j} \mathrm{C}^{*}}(\theta, \beta) .
\end{aligned}
$$

By using symmetry, the first-order condition becomes,

$$
\frac{\partial k^{i}}{\partial \theta}=\Pi_{z i}^{i} \frac{d z^{i}}{d \theta}+\Pi_{z j}^{i} \frac{d z^{j}}{d \theta}-\frac{\partial M^{i C^{*}}}{\partial \theta}-s^{\prime}\left(\theta^{i}\right)
$$

$15 \frac{\partial^{2} h^{i}}{\partial \theta^{i 2}} \frac{\partial^{2} h^{j}}{\partial \theta^{j 2}}-\frac{\partial^{2} h^{i}}{\partial \theta^{i} \partial \theta^{j}} \frac{\partial^{2} h^{j}}{\partial \theta^{i} \partial \theta^{j}}>0$ 


$$
\begin{aligned}
= & \left(\Pi_{z i}^{i}+\Pi_{z j}^{i}\right)\left\{\frac{\partial M^{C^{*}}}{\partial \theta}+\gamma^{C^{*}} M^{C^{*}}+\theta\left(\gamma_{M} \frac{\partial M^{C^{*}}}{\partial \theta} M^{C^{*}}+\gamma^{C^{*}} \frac{\partial M^{C^{*}}}{\partial \theta}\right)\right\} \\
& -\frac{\partial M^{C^{*}}}{\partial \theta}-s^{\prime}(\theta)=0 \quad \mathrm{i}=1,2
\end{aligned}
$$

A symmetric equilibrium for cooperative $\theta$, given $\beta$, is denoted here as $\theta^{\mathrm{ic}}(\beta)=\theta^{\mathrm{iC}^{*}}(\beta)=\theta^{\mathrm{C}^{*}}(\beta)$. $\theta^{\mathrm{C}^{*}}(\beta)$ is a solution of (9). It can be easily shown that there is at least one solution $\theta^{\mathrm{C}^{*}}$ which satisfies the first-order condition for any $\beta$.

It is not clear if $\theta^{C^{*}}(\beta)$, the equilibrium knowledge sharing rate in the cooperative $\theta$ case, is larger than $\theta^{\mathrm{NC}^{*}}(\beta)$, the equilibrium knowledge sharing rate in the non-cooperative case. However, we can show for large $\beta, \theta^{\mathrm{C}^{*}}(\beta)>\theta^{\mathrm{NC}^{*}}(\beta)$.

In the following analysis, it is necessary to establish signs of $\frac{\partial M^{i^{*}}}{\partial \theta^{j}}, \frac{\partial M^{j^{*}}}{\partial \theta^{j}}, \frac{\partial M^{*}}{\partial \theta}, \frac{\partial M^{*}}{\partial \beta}$, and $\frac{\partial^{2} M^{*}}{\partial \theta \partial \beta}$. Exploring these effects analytically is quite complex. Thus, to provide an intuitive sense of the basic forces at work, we simplify the analysis by considering only the first-order effects of knowledge, $\mathrm{z}$, on firm profit, following Cohen and Levinthal (1989). Because we cannot claim the analysis to apply generally, we provide a numerical example in Appendix 3 to confirm the intuition developed here.

Claim 1. For large $\beta, \theta^{\mathrm{C}^{*}}(\beta)>\theta^{\mathrm{NC}^{*}}(\beta)$.

Proof. See Appendix 1.

Claim 1 shows that when the knowledge firms possess is highly complementary, and if firms commit to share the knowledge at the same rate, the resulting knowledge sharing rate is greater than in the case where no such commitment exists. This proof can be explained in a different way from the analysis developed above. In the non-cooperative case, when an opponent chooses $\theta_{\mathrm{j}}$ in the interval we consider, firm i's best response is to choose a smaller $\theta_{i}$ than its opponent. That is because a larger $\theta_{i}$ 
unambiguously increases an opponent's stock of knowledge, and the benefit from an opponent's increased stock of knowledge (since some of it spills over to firm i) has only a secondary effect. However, since the cost function of $\theta$ is convex, to take a very small value of $\theta_{i}$ is extremely costly. Hence firm $i$ will choose a value of $\theta_{\mathrm{i}}$ which is smaller than $\theta$ as the solution of $\mathrm{s}^{\prime}(\theta)=0$, at which the cost of $\theta$ is minimized, equating the marginal benefit from taking smaller $\theta_{\mathrm{i}}$ and the marginal cost of $\theta_{\mathrm{i}}$.

When it is required that the same $\theta$ is chosen, firms find it is mutually beneficial to choose a larger $\theta$ than $\theta^{\mathrm{NC}^{*}}$. This is because, ceteris paribus, the larger $\theta$ increases the stock of knowledge and reduces marginal production costs of both firms, and Cournot competition implies larger profits for both firms. Also, since $\theta^{\mathrm{NC}^{*}}<\left.\theta\right|_{\mathrm{s}^{\prime}(\theta)=0}$, to increase $\theta$ cooperatively decreases the costs of $\theta$, at least until $\theta$ reaches $\left.\theta\right|_{s^{\prime}(\theta)=0}$. We have shown a numerical example in Appendix 3 with an exponential cost function and a linear learning capability function which satisfies $\theta^{\mathrm{C}^{*}}>\left.\theta\right|_{s^{\prime}(\theta)=0}$.

Can we draw the opposite conclusion when $\beta$ is small? It is ambiguous because an approximation in a previous proof is less justifiable when $\beta$ is small, which increases the value of $\gamma$, and which in turn increases the secondary effect of its own knowledge on the profit of the other firm.

Next, we examine if $\mathbf{M}^{\mathrm{C}^{*}}(\beta)>\mathbf{M}^{\mathrm{NC}}(\beta)$ holds or if cooperation in knowledge sharing increases private R\&D. For this proof, we basically follow Cohen and Levinthal (1989) and determine that the results depend on whether $\frac{\partial M^{*}}{\partial \theta}$ takes a positive sign or not.

Claim 2. For large $\beta, \mathbf{M}^{\mathrm{C}^{*}}(\beta)>\mathrm{M}^{\mathrm{NC}}(\beta)$.

Proof. See Appendix 2.

Claim 2 shows that when the knowledge firms posses is highly complementary, and if firms commit to share the knowledge at the same rate, the resulting $R \& D$ spending level by these firms is higher than in the case where no such commitment exists. Why does a cooperatively determined $\theta$ increase the $\mathrm{R} \& \mathrm{D}$ investment when $\beta$ is large? When $\beta$ is large, or firms possess more complementary knowledge 
stocks, firms are encouraged to invest in $R \& D$ because higher $\beta$ enhances the positive impact of own $\mathrm{R} \& \mathrm{D}$ on the other firm's knowledge that is successfully absorbed. Also, a higher $\beta$ implies a competitor's absorptive capacity level is smaller, therefore it encourages $R \& D$ by mitigating the appropriability problems of spillovers. A higher $\beta$ also increases the optimal level of R\&D by a competitor as well as the first firm, which decreases that firm's profit. However, as long as $\left|\Pi_{z \mathrm{i}}^{\mathrm{i}}\right|>\left|\Pi_{\mathrm{zj}}^{\mathrm{i}}\right|$ holds, the benefit from increased own R\&D exceeds the loss from increased competitor's R\&D. Therefore a higher $\beta$ encourages R\&D investment.

When $\theta$ becomes large, the pool of industry R\&D becomes large, which provides an incentive to conduct $\mathrm{R} \& \mathrm{D}$ in order to absorb more knowledge from others. When $\beta$ is also large, the level of the learning capability by a competitor becomes small, which means the disincentive associated with other firms' assimilation of the first firm's R\&D output becomes small. Therefore a cooperative increase in $\theta$ increases $R \& D$ investment by participating firms, which decreases the marginal production costs of both firms, and Cournot competition implies that this increases the profits of both firms.

This mechanism only works only if firms commit to increase $\theta$ cooperatively. Claim 1 implies that when $\beta$ is large, $\frac{\partial^{i}}{\partial \theta^{j}}>0$ at both $\theta$ are around the Nash equilibrium level. This means a competitor's increase in $\theta$ is beneficial for a firm when a firm does not change its own $\theta$, and a firm's increase in $\theta$ is beneficial for a competitor. Therefore, there is no incentive for a firm to increase $\theta$ voluntarily.

As with claim 1, the way this mechanism works when $\beta$ is small is ambiguous. It can be shown that $\frac{\partial M^{*}}{\partial \theta}<0$ when $\beta$ is small. However, it is not clear if firms can have an incentive to decrease $\theta$ cooperatively. That is because, from the previous argument, $\mathrm{s}^{\prime}\left(\theta^{\mathrm{NC} *}\right)<0$; this means the Nash equilibrium $\theta$ lies on the downward sloping side of the cost curve of $\theta$. A cooperative decrease in $\theta$ increases the cost of $\theta$, and it is not clear if the gain from increased $R \& D$ investment exceeds the increased cost. 


\subsubsection{Case of both $\theta$ and $M$ set cooperatively}

The third game is a case in which both the knowledge sharing rate $\theta$ and $R \& D$ investment $M$ are determined cooperatively. This case becomes a two-stage game where firms conduct Cournot competition during the second stage. In the first stage, given ßand Cournot quantity, and noting that $c^{i}\left(z^{i}\right)=c^{j}\left(z^{j}\right)=$ $\mathrm{c}(\mathrm{z})$ and $\mathrm{z}=\mathrm{M}+\gamma \theta \mathrm{M}$, a firm solves,

$$
\underset{M, \theta}{\operatorname{Max}} \mathrm{w}=\frac{1}{9 b}\{\mathrm{a}-\mathrm{c}(\mathrm{z})\}^{2}-\mathrm{M}-\mathrm{s}(\theta)
$$

First-order conditions are

$$
\begin{aligned}
& \frac{\partial w}{\partial M}=-\frac{2}{9 b}(a-c) \frac{\partial c}{\partial z}\left(1+\gamma \theta+\gamma_{M} \theta M\right)-1=0 \\
& \frac{\partial w}{\partial \theta}=-\frac{2}{9 b}(a-c) \frac{\partial c}{\partial z} \gamma M-s^{\prime}(\theta)=0
\end{aligned}
$$

Note $s^{\prime}(\theta) \geq 0$. From (9) and from (10), we get

$$
\mathbf{s}^{\prime}(\theta)\left(1+\gamma \theta+\gamma_{M} \theta \mathrm{M}\right)=\gamma \mathrm{M}
$$

Equilibrium $\theta$ and $M$ satisfy this condition. We cannot specify equilibrium $\theta$ and $M$ using only this condition. However, when the impact of R\&D on cost reduction is only incremental, i.e., when the absolute value of $\frac{\partial c}{\partial z}$ is not too large, ${ }^{16}$ it can be the case that $\frac{\partial w}{\partial M}$ is always negative, thus optimum $\mathrm{M}$ is given as a corner solution, i.e., $\mathbf{M}^{\mathrm{CC} *}=0$. Given this, optimum $\theta$, denoted $\theta^{\mathrm{CC} *}$, is obtained as the solution of $s^{\prime}(\theta)=0$. This result means that when both $\mathbf{M}$ and $\theta$ are determined cooperatively, it discourages $R \& D$ investment when $R \& D$ investment has only an incremental impact on cost reduction. In other words, competitive pressure forces firms to invest in $R \& D$ even if that $R \& D$ investment is not very profitable. A case with a linear demand function $\mathrm{D}^{-1}=4-\mathrm{Q}$, an exponential cost function $\mathrm{c}=\mathrm{e}^{-\mathrm{z}}$, and a

\footnotetext{
${ }^{16}$ Note that the previous assumption requires that $\Pi_{z i}^{\mathrm{i}}=-(4 / 9 \mathrm{~b})(\mathrm{a}-\mathrm{c}) \partial \mathrm{c} / \partial \mathrm{z}>1$, and therefore, the argument above holds in the range $9 \mathrm{~b} /\left\{2(\mathrm{a}-\mathrm{c})\left(1+\gamma \theta+\gamma_{\mathrm{M}} \theta \mathrm{M}\right)\right\} \geq|\partial \mathrm{c} / \partial \mathrm{z}|>9 \mathrm{~b} / 4(\mathrm{a}-\mathrm{c})$. In order for this inequality to be meaningful, $\gamma \theta+\gamma_{M} \theta M<1$ should hold in equilibrium. Given $0 \leq \gamma \leq 1,0 \leq \theta \leq 1$ and noting that the value of $M$ depends on the scaling, this inequality is not so restrictive.
} 
quadratic knowledge sharing cost function $s(\theta)=\{1 / 10 \tan \pi(\theta-1 / 2)\}^{2}$ satisfies this condition. The result is shown in Appendix 3.

For the case in which R\&D investment has a very large impact on cost reduction, the result depends on the gain from increased $R \& D$ investment and the cost associated with $\theta^{\mathrm{CC}^{*}}$, which is larger than $\theta$ at $s^{\prime}(\theta)=0$. In the reduced form it is difficult to specify if equilibrium $\mathrm{M}$ increases or not when $\mathbf{M}$ is determined cooperatively.

\subsubsection{Collusive case}

The forth case is a collusive case, in which quantity, R\&D investment, and the knowledge sharing rate are all cooperatively determined. Here we focus on a symmetric case in which both firms produce and invest the same amount. ${ }^{17}$ At stage two, collusive quantity is determined. At stage one, given monopoly quantity $\mathrm{Q}=2 \mathrm{q}=(\mathrm{a}-\mathrm{c}) / 2 \mathrm{~b}$ and taking $\mathrm{q}$ into consideration, a firm solves,

$$
\underset{M, \theta}{\operatorname{Max}} \mathrm{u}=\frac{1}{8 b}\{\mathrm{a}-\mathrm{c}(\mathrm{z})\}^{2}-\mathrm{M}-\mathrm{s}(\theta)
$$

The solution is the same as the cooperative $\theta$ and $\mathrm{M}$ case, i.e., $\mathrm{M}^{\mathrm{CO}}=0 ; \theta^{\mathrm{CO}}$ is given as the solution of $s^{\prime}(\theta)=0$ if this R\&D has only incremental impact. ${ }^{18}$

\subsection{Discussion}

This model shows that the equilibrium knowledge sharing rate and $R \& D$ investment are higher in the cooperative $\theta$ case than in the non-cooperative case when the knowledge of consortium participants is highly complementary. In this case, welfare is higher in the cooperative $\theta$ case, because firm profits and consumer surplus are higher given the higher R\&D level and the greater cost reduction. Because of this, governments have an incentive to promote R\&D consortia. On the other hand, if firms have substitutable knowledge, the impact of an $R \& D$ consortium on welfare becomes ambiguous. Therefore, this model

\footnotetext{
${ }^{17}$ One may consider an asymmetric case in which one firm is shut down and all the operation is done by the remaining firm. Here we limit our consideration to a symmetric case for a comparison with other cases, and we assume such an asymmetric case cannot happen because of capacity constraints and high shutdown costs.

${ }^{18}$ The analysis in this section is conducted for a duopoly case. The basic results hold for an n-firm case if we
} 
implies that antitrust law enforcement regarding cooperative $R \& D$ has to take the composition and knowledge complementarity of participating companies into consideration. Further, this model shows that if both the knowledge sharing rate and the level of $R \& D$ investment are determined cooperatively, $R \& D$ investment may be discouraged and consumer surplus may be reduced. In this case, social welfare may be lower than in the cooperative $\theta$ case. The same argument applies to the collusive case.

A numerical example presented in Appendix 3 illustrates the arguments above. In this example, the equilibrium knowledge sharing rate is always higher in the R\&D consortia case than in the noncooperative case. $R \& D$ expenditures also become higher in the $R \& D$ consortia case when $\beta$ is larger than 0.9 , and a combined result of those two effects is lower production cost in the R\&D consortia case when $\beta$ is larger than 0.75 . Since firm profits are always higher in the R\&D consortia case than the noncooperative case, welfare is higher in the $R \& D$ consortia case when $\beta$ is larger than 0.5 . The government, therefore, has an incentive to promote $R \& D$ consortia with high $\beta$. In this example, welfare in the R\&D consortia case is always higher than in the collusive cases.

\section{Empirical Analysis}

\subsection{Econometric specification}

In this section, we test a hypothesis derived from section 2 and the preceding model: participation in R\&D consortia with diverse participants increases firm R\&D spending. The equation we seek to estimate is:

$$
\begin{aligned}
& \log \left(R \& D_{i t}\right)=\alpha_{i}+\beta_{1} \log \left(\text { sales }_{i t}\right)+\beta_{2} \text { participation }_{i t}+\beta_{3} \text { participation }_{i t} * \text { diversity }_{i} \\
& +\beta_{4} \log \left({\text { government_subsidy })_{i t}}+\sum \delta_{t} \text { year }_{t}+\varepsilon_{i t}\right.
\end{aligned}
$$

where $R \& D_{i t}$ is firm i's $R \& D$ expenditures in year $t, \alpha_{i}$ is the individual effect, sales $s_{i t}$ is firm i's sales in year $t$, participation ${ }_{\mathrm{it}}$ is a dummy variable which takes 1 on the first and subsequent years of 
participation in an R\&D consortium by firm $i$, and 0 otherwise, diversity $y_{i}$ is the diversity measure of a consortium in which firm i participates, government_subsidy ${ }_{\mathrm{it}}$ is a government subsidy allocated to firm $\mathrm{i}$ in year $\mathrm{t}$, and the $\delta$ 's are the coefficients on year dummy variables, year. $\mathrm{t}_{\mathrm{t}}$. A full set of year dummies is included to control for macro business cycle effects, general trends of R\&D spending, and any effects of general technological opportunities. 1981 is used as a reference year. ${ }^{19}$ Firm sales is included as a control, and government subsidy is included to test if subsidies work as a complement or a substitute of firm R\&D.

One of the key variables in the estimated equation is diversity, the degree of heterogeneity among consortia participants' technological capabilities, denoted $\beta$ in the previous section. To calculate diversity, two methods are employed: one focuses on the diversity of participating firms' core businesses, and the other focuses on the technological diversity of participating firms.

Two measures of the diversity of participating firms' core businesses in each R\&D consortium are used. It is assumed that the degree of heterogeneity of knowledge stocks is greater between industries than within an industry. In other words, R\&D consortia members from more diverse industries are assumed to bring less overlapping and potentially more complementary knowledge. This measure requires the assumption that the firm's core technology resides in its main line of business.

The use of "heterogeneity in industry background" as a proxy for diversity is a potential source of measurement error. Some industries might consist of diverse groups of firms whose capabilities are highly differentiated, while firms in different industries may have similar skills. The technological "closeness" of industries, however, is reflected in the SIC classification, and one could argue that this is what the SIC classification is for (Griliches, 1992), and that the use of this proxy is justified.

The diversity measures of participants' core businesses we use here are drawn from the diversification literature. In this analysis, the diversity measures used in Montgomery (1982) and

\footnotetext{
${ }^{19}$ Because the natural log of zero is not identified, $R \& D$, sales, government budget variables are transformed by adding 1 to all observations and taking the $\log$ of this sum. This transformation is standard in the R\&D literature.
} 
Palepu (1985) are calculated for each R\&D consortium by using the 3-digit SIC codes of the participating firms' main businesses. These measures are Montgomery's 3-digit product count measures, and Palepu's total entropy measures. The details of the diversity measures' calculation and the method of main business identification are explained in Appendix 4. When all the participants are classified in the same 3-digit industry, both Montgomery and Palepu measures become zero. The maximum value Montgomery measures can take is one, while Palepu measures can exceed one.

The technological diversity of participating firms is measured as the average technological distance of participating firms in a consortium. This calculation is based on each firm's patent portfolio in fifty distinct technology fields. For each pair of firms in a consortium, the technological proximity is calculated by measuring the degree of similarity in their patent portfolios, and the average of the technological proximity for all the pairs in a consortium is a basis of the consortium's measure of technological diversity. The details of the calculation are explained in Appendix 5.

Though technological diversity is a better measure than diversity of participating firms' core businesses as a proxy for the diversity of technological expertise of consortia participants, the calculation requires us to identify the patent portfolio of all the participants in a consortium. This is a very time consuming process, and so in this analysis this calculation is conducted for $75 \%$ of the consortia in the sample, reducing the number of observations. ${ }^{20}$ Also, the patent portfolio of all the participants in a consortium are not necessary identified. In this analysis, the medium coverage per consortium is $67 \%$. Firms which are not included are typically small, unlisted firms. Because of these limitations, three diversity measures are used for this analysis to compensate for measurement error and to obtain robust estimates.

\subsection{Data}

\footnotetext{
${ }^{20}$ The technological diversity is calculated for 55 of the 73 consortia in the sample. There are 213 firms for the analysis with the technological diversity measure, which include 123 consortia participants and 100 consortia nonparticipants.
} 
The empirical analysis of this article focuses on R\&D consortia in Japan that were sponsored by government organizations. This form of cooperative $R \& D$ is chosen because these ventures are most frequently cited as being important to industry competitiveness, particularly among Western observers. In addition, comprehensive and detailed data are available for this type of R\&D consortia.

Government-sponsored R\&D consortia include all significant company-to-company cooperative R\&D projects formed with a degree of government involvement. The nature of government involvement in R\&D consortia varies. The government can have significant influence on the formation of consortia, including input in the type of participants who will be involved and the directions research will take. One means by which the government wields this influence is through subsidies to the consortia that meet established criteria. In this article, a principal criterion used to identify government-sponsored $R \& D$ consortia is that the projects of the $R \& D$ consortia involved cooperation among private companies. Projects which were primarily government procurement, and those in which government agencies simply allocated tasks without the private sector's initiative, were excluded. Projects which were essentially the implementation of existing technology were also excluded. ${ }^{21}$

A large number of government sponsored R\&D consortia occurred between 1959 and 1992, of which 237 were included in the data set. 1171 companies participated in these consortia during this period, and many were involved in multiple projects. Inclusion of these multiple projects yields a data set with 3021 company-project pairs. This data set was collected from each ministry through direct contacts after examining a wide range of government white papers and other government publications, and is as close as possible to an exhaustive list of all the government sponsored R\&D consortia in Japan during this time period. This data set was matched with the set of all first section Tokyo Stock Exchange firms whose $R \& D$ expenditures and sales figures are reported in the Japan Development Bank Financial Database (JDB). This matching process and the criteria explained below determined the number of observations included in this analysis. 
The sample for this empirical analysis consists of 267 firms which can be categorized in one of two sets: consortia participants and "matching" consortia non-participants. For consortia participants, the empirical analysis concentrates on the first cooperative R\&D project in which a particular firm participated. This criterion allows us to isolate the effect of a single project on a given participating firm. This set includes 155 consortia participants which reported their R\&D expenditures for at least six consecutive years including the first year of consortia participation and one year before and after the first year. The maximum window of observation per firm is 13 years, which includes six years before the participation, the first year of the participation, and six years after the first participation. This 6year "before" and "after" observation period is chosen because the average interval between the first consortia participation and the second consortia participation is at least 6.2 years for the sample firms, thus this window allows us to isolate the effect of the first project. The average duration of the R\&D consortia in the sample is 6.8 years, and so this 6 year "after" observation period should allow us to evaluate the total effect of the participation. Alternative to 13 years, an 11-year window is also tested.

For each consortium participant, a matching consortia non-participant is selected from the same SIC 3-digit industries with the same years of observation as the matched firm. Matching nonparticipants are included in the analysis in order to control for any bias which might arise from the characteristics of industries to which participants belong. Alternatively, a subsample of consortia participants are tested. The matching process might sound arbitrary. Only a limited number of potential matching firms report $R \& D$ expenditures consecutively for 6 years or longer, and so in most cases there is no room to arbitrarily choose matching firms from a limited pool. When several firms are available as matching firms, the one most similar in size is chosen as a match. This matching process yields 112 matching firms.

For each consortia participant, the government contribution per firm is calculated by dividing the yearly government subsidy to a consortium by the number of participants in the consortium. Only

\footnotetext{
${ }^{21}$ For a detailed explanation of government-sponsored R\&D consortia in Japan, see Sakakibara (1997b).
} 
the total government subsidy per consortium is available, and so it is assumed the subsidy is allocated uniformly over the entire project period. For a given firm, when a government subsidy from the second project in which a firm participates exceeds that of the first project, that year is dropped from the observation. From this procedure, an unbalanced panel data of 267 firms is obtained. The observation period per firm ranges from 6 to 13 years. $^{22}$ All financial data are real annual figures deflated to the base year 1985 using Japanese GDP deflators.

The firms in the sample represent 75 different 3-digit SIC industries; 73 different cooperative R\&D projects are covered. The first year the sample firms participated in the cooperative $R \& D$ projects ranges from 1971 to 1990 . The total period covered in this analysis is between 1969 and 1994. Table 1 and 2 report the summary statistics and a correlation matrix of the data.

Table 1 and 2 about here

\subsection{Results}

To test the hypothesis regarding the association between the participation in $R \& D$ consortia and firm R\&D spending, we focus on relative differences in $R \& D$ spending between the non-cooperative R\&D period and the R\&D consortia participation period. We use ordinary least squares regression analyses with fixed effects. The fixed effect model assumes that differences across firms (difference in propensities of $\mathrm{R} \& \mathrm{D}$ spending across firms in this analysis) can be captured in the constant term. Operationally, we define transformations of our variables such that, for each firm in each year, we subtract the mean of the variable for that firm over time..$^{23}$

The fixed effect model allows us to emphasize the time-series or evolutionary dimension of the data $^{24}$, because all the industry-specific effects, and the unmeasured firm-specific effects which might

\footnotetext{
${ }^{22}$ This variation also comes from the missing R\&D reporting of some sample firms.

${ }^{23}$ For an example of the fixed effect model to measure determinants of firm-level R\&D, see Branstetter and Sakakibara (1998). For an use of the fixed effect model to evaluate the effects of different regulatory periods, see Kole and Lehn (1996).

${ }^{24} \mathrm{~A}$ cost of this technique is that standard goodness-of-fit measures are uninformative. We report adjusted $\mathrm{R}^{2}$
} 
have been included in the error term fall out in the process of the transformation of the variables, since they do not vary "within firms" over time. This methodology, therefore, is appropriate in this analysis because it allows us to focus on changes in $R \& D$ under two different periods, the R\&D consortia nonparticipation period and the consortia participation period. Moreover, this methodology has a clear advantage when dealing with Japanese firm-level R\&D data. Many researchers (for example, Griliches and Mairesse 1990) noted the poor and inconsistent reporting of R\&D figures across Japanese firms. This is partly because the coverage of R\&D figures of Japanese firms is less standardized than that of the U.S. Process R\&D performed on the factory floor, for instance, might or might not be included as R\&D spending for some firms, though this is an important $R \& D$ activity by Japanese firms. This inconsistency across firms becomes a major source of noise for a cross-section analysis. The fixed effect approach, however, should be valid even if there are large differences in R\&D reporting standards across firms, as long as firms are consistent in their reporting policies over time. Japanese CPAs have noted that for a given firm, the coverage of R\&D figures is consistent over time, supporting the validity of this methodology.

Table 3 about here

Table 3 reports estimation results. Standard errors are heteroskedasticity-robust standard errors computed by using the formulas suggested by White (1980). Regression (1) is the base case, in which only a dummy variable of consortia participation is included without controlling for the diversity of consortia. The coefficient of the participation dummy variable is positive and significant at the $1 \%$ level, indicating that, all else being equal, participation in an R\&D consortium on average increases firm R\&D spending by $23 \%$. In this specification, the coefficient of the log of per-firm government subsidy is negative and significant at the $5 \%$ level, indicating a negative impact of government subsidy on firm R\&D spending. The magnitude of this substitution effect, however, is small. A $100 \%$ increase 
in the per-firm government subsidy decreases firm R\&D expenditures by only $3.6 \%$.

Regressions (2) through (4) include an interaction term in which the participation dummy is multiplied by one of the consortia diversity measures to evaluate the marginal effect of the diversity of the consortia. In regression (2), the Montgomery diversity measure is used. The coefficient of the participation dummy is negative and significant at the $1 \%$ level, and the interaction term is positive and significant at the $1 \%$ level. This result implies that when a firm participates in a consortium in which all the participants come from a single industry, all else being equal, annual firm R\&D expenditures decrease by $34 \%$; this implies that the cost-sharing consortia economize substantially on firm R\&D spending. When the diversity measure increases by $10 \%$, however, firm R\&D expenditures increase by $7 \%$. This implies that for firms which participate in highly diversified consortia, with the diversity measure equal to one, this knowledge-sharing effect increases firm R\&D expenditures by $72 \%$, and the total effect of the participation in highly diversified consortia is to increase firm R\&D expenditures by $38 \%$ (i.e. the sum of $-34 \%$ by the participation effect and $72 \%$ by the knowledge-sharing effect). In this specification, the coefficient of the log of per-firm government subsidy is, again, negative and statistically significant at the $5 \%$ level, and the $100 \%$ increase in the per-firm government subsidy decreases firm R\&D expenditures by only $3.6 \%$.

Another way of interpreting these results is that, when a firm participates in an average R\&D consortium $^{25}$, the participation itself decreases the firm's R\&D expenditures by $34 \%$, the diversity or knowledge-sharing effect increases R\&D expenditures by $57 \%$, and the government subsidy effect decreases $R \& D$ expenditures by $11 \%$. The sum of these three effects is a $13 \%$ increase in the average firm's R\&D expenditures. Regression (3), with Palepu entropy diversity measure, yields qualitatively similar results, with a slightly worse goodness-of-fit. The sum of the three effects of the participation

\footnotetext{
${ }^{25}$ The mean of government subsidies in this sample is 54.3 million yen, with the log transformation by adding one yielding 2.93. The mean of Montgomery measure of the sample is 0.8 .
} 
in an average consortium, as mentioned above, is also a $13 \%$ increase in R\&D spending. ${ }^{26}$

Regression (4), with the technological diversity measure, yields qualitatively similar results, confirming the robustness of the findings. In this specification, the coefficient of the participation dummy is not significant, though it is negative. Again, the coefficient of the interaction term of the participation dummy and the diversity measure is positive and significant at the $1 \%$ level, indicating that when the diversity measure increases by $10 \%$, firm R\&D expenditures increase by $4.3 \%$. The sum of the three effects of the participation in an average consortium with this specification is a $10 \%$ increase in R\&D spending. ${ }^{27}$

Regressions (5) through (7) are cases in which the project scale is controlled. The project scale is measured as the project budget (including government subsidy) per firm per year. Since this variable is highly correlated with the government subsidy variable, the results should be interpreted with caution. The basic results hold for all the specifications, with the major difference from regressions (2) through (4) being the significance of the government subsidy variable.

Table 4 about here

In order to test the robustness of the results obtained from fixed effect models, two alternative methodologies are tested. First, since a firm's negative R\&D spending is not observed (i.e. R\&D data is left-censored), Tobit models are used to address this issue. ${ }^{28}$ Second, fixed effect models assume that the company-specific intercepts do not have a distribution, while random effect models assume that the intercepts are drawn from a common distribution. Table 4 reports results of Tobit and random effect estimations. Both estimates yield coefficients of our focus with almost the same magnitude and

\footnotetext{
${ }^{26}$ A subsample of balanced panel data, and a subsumple of consortia participants were tested and yielded qualitatively similar results.

${ }^{27}$ Also, variants of regressions (2) through (4) are tested in which 11-year observation periods, five years before the participation, the year of the first participation, and five years after the participation are used. These regressions yield qualitatively similar results to regressions (2) through (4).

${ }^{28}$ Tobit estimates for panel data are not readily available in the statistical software used in this analysis. Operationally, therefore, Tobit estimates were conducted by including a full set of company dummies.
} 
significance as those from fixed effect estimates, supporting the robustness of the results. ${ }^{29}$

\section{Conclusions}

This article examines the effects of knowledge sharing or endogenous spillovers among R\&D consortia participants on $R \& D$ competition when $R \& D$ enhances a firm's absorptive capacity. A gametheoretic model illustrates how different compositions of $R \& D$ consortia affect spillovers and $R \& D$ spending of participants. When a firm participates in a consortium whose members are from diverse industries, the model suggests that this participation increases spillover rates among participants and intensifies firms' $R \& D$ efforts to learn from other members in the consortium. An econometric analysis based on the panel data of 267 Japanese firms over 13 years shows evidence of this learning effect. This finding is consistent with Sakakibara (1997a), which is based on survey data. In addition, this analysis finds that government subsidies to consortia are likely to decrease the R\&D spending of participating firms, though the magnitude is found to be small.

The results of this article shed light on conflicting findings by previous literature. Irwin and Klenow (1996) found that SEMATECH reduced the semiconductor industry's R\&D spending by $9 \%$, while Branstetter and Sakakibara (1998) found that, on average, if a firm participates in an additional Japanese government-sponsored R\&D consortium, it will raise its total annual R\&D spending by about 2\%. SEMATECH is a consortium in which a narrow set of industries (semiconductor makers and fabrication equipment makers) participate, and so the implied diversity measure should will be very small; in this consortium, the cost-sharing effect among participants - which reduces firm R\&D spending - dominates. An average Japanese government-sponsored R\&D consortium consists of firms from much more diverse industries; in these consortia, the knowledge-sharing effect illustrated in this article dominates.

\footnotetext{
${ }^{29}$ It is confirmed that a Hausman test cannot reject the equivalence of random effects and fixed effects models at the $5 \%$ level.
} 
In this article, the magnitude of the effect of the participation in an R\&D consortium on firm R\&D expenditures is found to be between $10 \%$ and $13 \%$, on average. This effect is much larger than the $2 \%$ found by Branstetter and Sakakibara (1998). Their observation period is from 1983 to 1989. In contrast, this analysis covers the period from 1969 to 1994 , including a much earlier period. One possible interpretation of the difference of these results is that the first participation in an R\&D consortium, which is the focus of this analysis, has the greatest impact. After a firm repeatedly participates in $R \& D$ consortia, the marginal effect of participation diminishes because firms increase their capabilities to learn from others.

This article also indicates that government subsidies work as a substitute to firm $R \& D$, though the magnitude of this effect is small. In contrast, Sakakibara (1997b) found from survey data that, on average, firms increased their $\mathrm{R} \& \mathrm{D}$ investment by $38 \%$ in the area related to the governmentsponsored $R \& D$ consortia compared with the hypothetical case that they did not participate in $R \& D$ consortia. Taken together, perhaps firms which participate in R\&D consortia might allocate more internal funding to technological areas supported by government-sponsored R\&D consortia. The total effect of the participation of $R \& D$ consortia on $R \& D$ spending, of course, depends on the knowledge sharing effect.

This article has an important implication for public policy. If the purpose of promoting R\&D consortia is to stimulate $\mathrm{R} \& \mathrm{D}$ competition, governments should take the organization of R\&D consortia into account when deciding on the types of R\&D consortia they want to promote. The membership of an $R \& D$ consortium can be a key determinant of whether the consortium contributes to the increase of private $R \& D$ efforts or not.

There are limitations to this analysis. First, the R\&D activities of many firms in the sample are diversified, and so ideally the dependent variable in the empirical analysis should be R\&D spending which is closely related with consortia activities. In this article, we use firm level R\&D spending which includes spending on all types of R\&D. Though this aggregation problem is a source of 
measurement error, it is not possible to obtain more disaggregated firm R\&D data at this time.

Also, though this analysis suggests an increase in $R \& D$ spending for participants in consortia with heterogeneous members, the productivity of such consortia is not yet examined. This is an issue which should be explored in future research in this area.

More research on cooperative $R \& D$ is necessary and should be encouraged. This article suggests R\&D consortia with different organizations can provide different impacts on participating firms. A future direction for this line of research includes more analyses at the project level, including the outcomes of the projects and determinants of these outcomes. Rigorous evaluations of one of the most prominent Japanese industrial policies will provide useful lessons to other countries which seek to emulate this Japanese practice. 
Table 1 Summary statistics

Panel A: All firms (Number of observations: 2949)

\begin{tabular}{lrrrr}
\hline & Mean & S.D. & Minimum & Maximum \\
\hline Sales & 134,045 & 216,966 & 2,811 & $2,675,592$ \\
R\&D & $2,207.4$ & $9,262.8$ & 1.1 & $177,915.4$ \\
Government subsidy per firm & 15.8 & 55.8 & 0.0 & 977.3 \\
\hline
\end{tabular}

Sales, R\&D, government subsidy per firm are million yen in 1985 prices.

Panel B: Consortia participants (Number of observations: 1671)

\begin{tabular}{lrrrr}
\hline & Mean & S.D. & Minimum & Maximum \\
\hline Sales & 194,525 & 266,443 & 9,334 & $2,675,592$ \\
R\&D & $3,367.6$ & $12,116.2$ & 3.5 & $177,915.4$ \\
Government subsidy per firm & 27.8 & 71.8 & 0.0 & 977.3 \\
Project scale (per firm) & 40.7 & 145.1 & 0.0 & 2131.7 \\
Montgomery diversity measure & 0.79 & 0.17 & 0.00 & 0.95 \\
Palepu entropy diversity measure & 1.93 & 0.55 & 0.00 & 2.79 \\
Technological diversity measure & 0.63 & 0.18 & 0.16 & 0.85 \\
\hline
\end{tabular}

Sales, $R \& D$, government subsidy per firm are million yen in 1985 prices. The technological diversity measure is from 1332 observations.

Panel C: Consortia non-participants (Number of observations: 1278)

\begin{tabular}{lrrrr}
\hline & Mean & S.D. & Minimum & Maximum \\
\hline Sales & 54,966 & 69,197 & 2,811 & 571,538 \\
R\&D & 690.3 & $1,422.3$ & 1.1 & $9,528.5$ \\
\hline
\end{tabular}

Sales and R\&D are million yen in 1985 prices.

\section{Table 2 Correlation matrix}

Panel A: All firms (Number of observations: 2949)

\begin{tabular}{llrrr}
\hline & 1 & 2 & 3 \\
\hline 1 & $\log ($ R\&D) & - & & \\
2 & $\log ($ sales $)$ & 0.59 & - & \\
3 & $\log ($ government subsidy per firm) & 0.24 & 0.28 & - \\
\hline
\end{tabular}

Panel B: Consortia participants (Number of observations: 1671)

\begin{tabular}{llrrrrrr}
\hline & 1 & 2 & 3 & 4 & 5 & 6 \\
\hline 1 & $\log (\mathrm{R} \& D)$ & - & & & & & \\
2 & $\log ($ sales $)$ & 0.55 & - & & & & \\
3 & $\log$ (government subsidy per firm) & 0.09 & 0.09 & - & & & \\
4 & $\log$ (project scale per firm) & 0.09 & 0.08 & 0.98 & - & & \\
5 & Montgomery diversity measure & -0.16 & 0.00 & 0.02 & -0.01 & - & - \\
6 Palepu entropy diversity measure & -0.17 & 0.02 & 0.01 & -0.02 & 0.95 & - \\
7 Technological diversity measure & -0.29 & -0.11 & 0.03 & 0.01 & 0.47 & 0.57 \\
\hline
\end{tabular}

The technological diversity measure is from 1332 observations. 
Table 3 Estimation of R\&D expenditure equation

Dependent variable: log of real R\&D spending by firms

OLS regressions with fixed effects

13-year window

\begin{tabular}{|c|c|c|c|c|c|c|c|}
\hline \multirow[t]{2}{*}{ Variables } & \multicolumn{4}{|c|}{ Base models } & \multicolumn{3}{|c|}{ With project scale variable } \\
\hline & $\begin{array}{l}(1) \\
\text { Participa- } \\
\text { tion } \\
\text { dummy } \\
\text { only } \\
\end{array}$ & $\begin{array}{l}\text { (2) With } \\
\text { Montgo- } \\
\text { mery } \\
\text { diversity } \\
\text { measure }\end{array}$ & $\begin{array}{l}\text { (3) With } \\
\text { Palepu } \\
\text { entropy } \\
\text { diversity } \\
\text { measure }\end{array}$ & $\begin{array}{l}\text { (4) With } \\
\text { technolo- } \\
\text { gical } \\
\text { diversity } \\
\text { measure }\end{array}$ & $\begin{array}{l}\text { (5) With } \\
\text { Montgo- } \\
\text { mery } \\
\text { diversity } \\
\text { measure }\end{array}$ & $\begin{array}{l}\text { (6) With } \\
\text { Palepu } \\
\text { entropy } \\
\text { diversity } \\
\text { measure }\end{array}$ & $\begin{array}{l}\text { (7) With } \\
\text { technolo- } \\
\text { gical } \\
\text { diversity } \\
\text { measure }\end{array}$ \\
\hline $\log$ (sales) & $\begin{array}{l}.465 \\
(5.92)^{* * *}\end{array}$ & $\begin{array}{l}.477 \\
(6.07)^{* * *}\end{array}$ & $\begin{array}{l}.477 \\
(6.06)^{* * *}\end{array}$ & $\begin{array}{l}370 \\
(4.06)^{* * *}\end{array}$ & $\begin{array}{l}.477 \\
(6.07)^{* * *}\end{array}$ & $\begin{array}{l}.477 \\
(6.06)^{* * *}\end{array}$ & $\begin{array}{l}.364 \\
(4.01)^{* * *}\end{array}$ \\
\hline $\begin{array}{l}\text { Consortia } \\
\text { participation } \\
\text { (dummy) }\end{array}$ & $\begin{array}{l}.232 \\
(4.30)^{* * *}\end{array}$ & $\begin{array}{l}-.338 \\
(-2.98)^{* * *}\end{array}$ & $\begin{array}{l}-.176 \\
(-2.02)^{* *}\end{array}$ & $\begin{array}{l}-.082 \\
(-.925)\end{array}$ & $\begin{array}{l}-.334 \\
(-2.80)^{* * *}\end{array}$ & $\begin{array}{l}-.176 \\
(-1.81)^{*}\end{array}$ & $\begin{array}{l}-.278 \\
(-2.56)^{* *}\end{array}$ \\
\hline $\begin{array}{l}\text { Participation * } \\
\text { Diversity } \\
\text { measure }\end{array}$ & & $\begin{array}{l}.717 \\
(5.62)^{* * *}\end{array}$ & $\begin{array}{l}.212 \\
(5.62)^{* * *}\end{array}$ & $\begin{array}{l}.431 \\
(3.33)^{* * *}\end{array}$ & $\begin{array}{l}.715 \\
(5.72)^{* * *}\end{array}$ & $\begin{array}{l}.212 \\
(5.67)^{* * *}\end{array}$ & $\begin{array}{l}.545 \\
(4.02)^{* * *}\end{array}$ \\
\hline $\begin{array}{l}\log \text { (government } \\
\text { subsidy) }\end{array}$ & $\begin{array}{l}-.036 \\
(-2.47)^{* *}\end{array}$ & $\begin{array}{l}-.036 \\
(-2.46)^{* *}\end{array}$ & $\begin{array}{l}-.037 \\
(-2.53)^{* *}\end{array}$ & $\begin{array}{l}-.032 \\
(-1.77)^{*}\end{array}$ & $\begin{array}{l}-.031 \\
(-.403) \\
\end{array}$ & $\begin{array}{l}-.037 \\
(-.477) \\
\end{array}$ & $\begin{array}{l}-.302 \\
(-3.97)^{* * *}\end{array}$ \\
\hline $\begin{array}{l}\log (\text { project } \\
\text { scale) }\end{array}$ & & & & & $\begin{array}{l}-.0052 \\
(-.066) \\
\end{array}$ & $\begin{array}{l}.00031 \\
(.0039) \\
\end{array}$ & $\begin{array}{l}.280 \\
(3.64)^{* * *}\end{array}$ \\
\hline Year dummies & significant & significant & significant & significant & significant & significant & significant \\
\hline $\begin{array}{l}\text { Number of } \\
\text { observations }\end{array}$ & 2949 & 2949 & 2949 & 2364 & 2949 & 2949 & 2364 \\
\hline Adjusted $\mathrm{R}^{2}$ & .934 & .935 & .934 & .942 & .934 & .934 & .943 \\
\hline
\end{tabular}


Table 4 Estimation of R\&D expenditure equation: robustness test

Dependent variable: log of real R\&D spending by firms 13-year window

\begin{tabular}{|c|c|c|c|c|c|c|}
\hline \multirow[t]{2}{*}{ Variables } & \multicolumn{3}{|l|}{ Tobit } & \multicolumn{3}{|c|}{ Random effect GLS } \\
\hline & $\begin{array}{l}\text { (1)With } \\
\text { Montgome- } \\
\text { ry } \\
\text { diversity } \\
\text { measure }\end{array}$ & $\begin{array}{l}\text { (2) With } \\
\text { Palepu } \\
\text { entropy } \\
\text { diversity } \\
\text { measure }\end{array}$ & $\begin{array}{l}\text { (3) With } \\
\text { technologi- } \\
\text { cal } \\
\text { diversity } \\
\text { measure }\end{array}$ & $\begin{array}{l}\text { (4) With } \\
\text { Montgome- } \\
\text { ry } \\
\text { diversity } \\
\text { measure }\end{array}$ & $\begin{array}{l}\text { (5) With } \\
\text { Palepu } \\
\text { entropy } \\
\text { diversity } \\
\text { measure }\end{array}$ & $\begin{array}{l}\text { (6) With } \\
\text { technologi- } \\
\text { cal } \\
\text { diversity } \\
\text { measure }\end{array}$ \\
\hline $\log ($ sales $)$ & $\begin{array}{l}.477 \\
(9.34)^{* \times *}\end{array}$ & $\begin{array}{l}.477 \\
(9.33)^{* * *}\end{array}$ & $\begin{array}{l}.370 \\
(6.62)^{* * *}\end{array}$ & $\begin{array}{l}.649 \\
(15.19)^{* * *}\end{array}$ & $\begin{array}{l}.649 \\
(15.19)^{* * *}\end{array}$ & $\begin{array}{l}.581 \\
(12.17)^{* * *}\end{array}$ \\
\hline $\begin{array}{l}\text { Consortia } \\
\text { participation } \\
\text { (dummy) }\end{array}$ & $\begin{array}{l}-.338 \\
(-2.71)^{* * *}\end{array}$ & $\begin{array}{l}-.176 \\
(-1.80)^{*}\end{array}$ & $\begin{array}{l}-.082 \\
(-.767)\end{array}$ & $\begin{array}{l}-.316 \\
(-2.42)^{* *}\end{array}$ & $\begin{array}{l}-.152 \\
(-1.48)\end{array}$ & $\begin{array}{l}-.021 \\
(-.182)\end{array}$ \\
\hline $\begin{array}{l}\text { Participation * } \\
\text { Diversity } \\
\text { measure }\end{array}$ & $\begin{array}{l}.717 \\
(5.00)^{* * *}\end{array}$ & $\begin{array}{l}.212 \\
(4.88)^{* * *}\end{array}$ & $\begin{array}{l}.431 \\
(3.06)^{* * *}\end{array}$ & $\begin{array}{l}.707 \\
(4.71)^{* * *}\end{array}$ & $\begin{array}{l}.207 \\
(4.55)^{* * *}\end{array}$ & $\begin{array}{l}.386 \\
(2.61)^{* * *}\end{array}$ \\
\hline $\begin{array}{l}\text { log(government } \\
\text { subsidy) }\end{array}$ & $\begin{array}{l}.036 \\
(-2.58)^{* * *}\end{array}$ & $\begin{array}{l}-.037 \\
(-2.66)^{* * *}\end{array}$ & $\begin{array}{l}-.032 \\
(-1.80)^{*} \\
\end{array}$ & $\begin{array}{l}-.040 \\
(-2.76)^{* * *}\end{array}$ & $\begin{array}{l}-.041 \\
(-2.84)^{* * *}\end{array}$ & $\begin{array}{l}-.042 \\
(-2.26)^{* *}\end{array}$ \\
\hline Constant & $\begin{array}{l}-.207 \\
(-.314) \\
\end{array}$ & $\begin{array}{l}.211 \\
(-.320) \\
\end{array}$ & $\begin{array}{l}-.711 \\
(-.957) \\
\end{array}$ & $\begin{array}{l}-1.42 \\
(-2.93)^{* * *}\end{array}$ & $\begin{array}{l}-1.42 \\
(-2.93)^{* * *}\end{array}$ & $\begin{array}{l}-.591 \\
(-1.10) \\
\end{array}$ \\
\hline Year dummies & significant & significant & significant & significant & significant & significant \\
\hline $\begin{array}{l}\text { Number of } \\
\text { observations }\end{array}$ & 2949 & 2949 & 2364 & 2949 & 2949 & 2364 \\
\hline Adjusted $\mathrm{R}^{2}$ & & & & .927 & .940 & .936 \\
\hline
\end{tabular}

Note: T-statistics in parentheses. $* * *$ significant at the $1 \%$ level, $* *$ significant at the $5 \%$ level, $*$ significant at the $10 \%$ level, using a two-tailed t-test. 


\section{Appendix 1. Proof of Claim 1}

From (7) and by definition of a symmetric Nash equilibrium, firm i's net profit becomes $\mathrm{h}^{\mathrm{i}}\left(\theta^{N C^{*}}, \theta^{\mathrm{NC}}, \beta\right) \geq \mathrm{h}^{\mathrm{i}}\left(\theta^{\mathrm{C}^{*}}, \theta^{\mathrm{NC}}, \beta\right)$

By choosing $\theta$ cooperatively, firms can perform at least as well as in the non-cooperative case, $\mathrm{h}^{\mathrm{i}}\left(\theta^{\mathrm{C}^{*}}, \theta^{\mathrm{C}^{*}}, \beta\right) \geq \mathrm{h}^{\mathrm{i}}\left(\theta^{\mathrm{NC}}, \theta^{\mathrm{NC}}, \beta\right)$

By adding these two inequalities, we get

$$
\mathrm{h}^{\mathrm{i}}\left(\theta^{\mathrm{C}^{*}}, \theta^{\mathrm{C}^{*}}, \beta\right) \geq \mathrm{h}^{\mathrm{i}}\left(\theta^{\mathrm{C}^{*}}, \theta^{\mathrm{NC}}, \beta\right)
$$

Which implies that

$$
\theta^{\mathrm{C}^{*}}>\theta^{\mathrm{NC}} \text { if } \frac{\partial^{i}}{\partial \theta^{j}}>0 \text { holds at all } \theta^{\mathrm{j}} \text { in the interval } \theta^{\mathrm{j}} \in\left(\theta^{\mathrm{NC}^{*}}, \theta^{\mathrm{C}^{*}}\right) \text { at } \theta^{\mathrm{i}}=\theta^{\mathrm{C}^{*}} .
$$

Examining $\frac{{\partial h^{i}}^{j}}{\partial \theta^{j}}$

$$
\begin{aligned}
\frac{\partial^{i}}{\partial \theta^{j}}= & \Pi_{z i}^{i} \frac{d z^{i}}{d \theta^{j}}+\Pi_{z j}^{i} \frac{d z^{j}}{d \theta^{j}}-\frac{\partial M^{i^{*}}}{\partial \theta^{j}} \\
= & \Pi_{z i}^{i}\left\{\frac{\partial M^{i^{*}}}{\partial \theta^{j}}+\gamma^{i} M^{j}+\theta^{j}\left(\gamma_{M i}^{i} \frac{\partial M^{i^{*}}}{\partial \theta^{j}} M^{j^{*}}+\gamma^{i} \frac{\partial M^{j^{*}}}{\partial \theta^{j}}\right)\right\} \\
& +\Pi_{z j}^{i}\left\{\frac{\partial M^{j^{*}}}{\partial \theta^{j}}+\theta^{i}\left(\gamma_{M j}^{j} \frac{\partial M^{j^{*}}}{\partial \theta^{j}} M^{i^{*}}+\gamma^{j} \frac{\partial M^{i^{*}}}{\partial \theta^{j}}\right)\right\}-\frac{\partial M^{i^{*}}}{\partial \theta^{j}}
\end{aligned}
$$

Also, we can show $\frac{\partial M^{i^{*}}}{\partial \theta^{j}}>0, \frac{\partial M^{j^{*}}}{\partial \theta^{j}}<0$ by considering only the first-order effects of $\mathrm{z}$ on a firm's profit.

Note (4) can be written as a function of $\mathbf{M}^{\mathrm{i} *}, \mathbf{M}^{\mathrm{j}}, \theta^{\mathrm{i}}, \theta^{\mathrm{j}}, \beta$,

$$
\frac{\partial g^{i}\left(M^{i^{*}}, M^{j}, \theta^{i}, \theta^{j}, \beta\right)}{\partial M^{i}}=0
$$

$\mathrm{M}^{\mathrm{i}^{*}}$ is defined as a solution of (12), given other variables. Differentiating (12) with respect to $\theta^{\mathrm{i}}$,

$$
\frac{\partial}{\partial \theta^{i}}\left[\frac{\partial g^{i}\left\{M^{i^{*}}\left(\theta^{i}\right), M^{j}, \theta^{i}, \theta^{j}, \beta\right\}}{\partial M^{i}}\right]=0
$$

From (13), we get

$$
\frac{\partial M^{i^{*}}}{\partial \theta^{i}}=-\frac{\frac{\partial^{2} g^{i}}{\partial \theta^{i} \partial M^{i *}}}{\frac{\partial^{2} g^{i}}{\partial M^{i^{*} 2}}}
$$

From the second-order condition (5), $\frac{\partial^{2} g^{i}}{\partial M^{i^{*}}}$ is always negative. To check the numerator, differentiating (12) with respect to $\theta^{\mathrm{i}}$,

$$
\frac{\partial^{2} g^{i}}{\partial \theta^{i} \partial M^{i^{*}}}=\Pi_{z j}^{i} \gamma^{j}+\Pi_{z i z j}^{i} \gamma^{j} M^{i}\left(1+\gamma_{M i}^{i} \theta^{j} M^{j}\right)+\Pi_{z j z j}^{i} \theta^{i} \gamma^{j 2} M^{i}
$$

If we focus only on first-order effects of $z$ on profit, $\Pi_{z j}^{i} \gamma^{j}$, this equation is negative. Therefore 


$$
\frac{\partial M^{i^{*}}}{\partial \theta^{i}}=\frac{\partial M^{j^{*}}}{\partial \theta^{j}}<0
$$

$$
\text { Similarly, } \frac{\partial M^{j^{*}}}{\partial \theta^{i}}=\frac{\partial M^{i^{*}}}{\partial \theta^{j}}=-\frac{\frac{\partial^{2} g^{i}}{\partial \theta^{j} \partial M^{i^{*}}}}{\frac{\partial^{2} g^{i}}{\partial M^{i * 2}}}
$$

From (5), $\frac{\partial^{2} g^{i}}{\partial M^{i^{* 2}}}$ is always negative. To check the numerator, differentiating (12) with respect to $\theta^{j}$,

$$
\frac{\partial^{2} g^{i}}{\partial \theta^{j} \partial M^{i^{*}}}=\Pi_{z i}^{i} \gamma_{M i}^{i} M^{j}+\Pi_{z i z i}^{i} \gamma^{i} M^{j}\left(1+\gamma_{M i}^{i} \theta^{j} M^{j}\right)+\Pi_{z i z j}^{i} \theta^{i} \gamma^{i} \gamma^{j} M^{j}
$$

If we focus only on first-order effects of $\mathrm{z}$ on profit, $\Pi_{\mathrm{zi}}^{\mathrm{i}} \gamma_{\mathrm{Mi}}^{\mathrm{i}} \mathrm{M}^{\mathrm{j}}$, this equation is positive. Therefore $\frac{\partial M^{i *}}{\partial \theta^{j}}=\frac{\partial M^{j^{*}}}{\partial \theta^{i}}>0$.

From the construction of $z^{i}=M^{i}+\gamma^{i}\left(M^{i}, \beta\right) \theta^{j} M^{j}$, the change of $\theta^{j}$ on $z^{i}$ comes from two sources; one is through the change of its own investment $\mathrm{M}^{\mathrm{i}}$, and the other is through the change of an opponent's investment $\mathrm{M}^{\mathrm{j}}$, multiplied by its own learning capability $\gamma^{\mathrm{i}}$ and an opponent's knowledge sharing rate $\theta^{j}$. Here we only consider the case in the interval $\theta^{\mathrm{j}} \in\left(\theta^{\mathrm{NC}}, \theta^{\mathrm{C}}\right)$. From the assumption on the cost function of $\theta, s(1)=\infty, \theta^{j}$ in this interval takes a value which is smaller than 1 . Also, when $\beta$ is large, from assumptions of $\gamma_{\beta}<0$ and $0 \leq \gamma \leq 1, \gamma$ takes a value which is much smaller than 1 . Therefore, the effect of the change of an opponent's investment on $z^{i}$ is dampened, and so we can approximate that $\frac{d z^{i}}{d \theta^{j}}=\frac{\partial M^{i^{*}}}{\partial \theta^{j}}$. The same logic applies to $\frac{d z^{j}}{d \theta^{j}}$, and so we can approximate that

$$
\frac{\partial h^{i}}{\partial \theta^{j}}=\Pi_{z i}^{i} \frac{\partial M^{i^{*}}}{\partial \theta^{j}}+\Pi_{z j}^{i} \frac{\partial M^{j^{*}}}{\partial \theta^{j}}-\frac{\partial M^{i^{*}}}{\partial \theta^{j}}
$$

This is positive by the assumption that $\Pi_{\mathrm{zi}}^{\mathrm{i}}>1$. We can therefore conclude that $\frac{\partial h^{i}}{\partial \theta^{j}}>0$ at $\theta^{\mathrm{i}}=\theta^{\mathrm{C}^{*}}, \theta^{\mathrm{j}}$ $\in\left(\theta^{\mathrm{NC}}, \theta^{\mathrm{C}^{*}}\right)$ which implies $\theta^{\mathrm{C}^{*}}(\beta)>\theta^{\mathrm{NC}}(\beta)$. 


\section{Appendix 2. Proof of Claim 2}

From Claim 1, as a proof of Claim 2 it suffices to show $\frac{\partial M^{*}}{\partial \theta}>0$ for large $\beta$, where $\mathrm{M}^{*}$ is the equilibrium value of each firm's $R \& D$ for a given $\theta$ (which is determined either cooperatively or noncooperatively). For this proof, we follow Cohen and Levinthal (1989) and Dixit (1986).

Differentiating firm i's gross earnings $\Pi^{\mathrm{i}}$ with respect to $\mathbf{M}^{\mathrm{i}}$ yields,

$$
R \equiv \Pi_{z i}^{i}\left(1+\gamma_{M i}^{i} \theta M^{j}\right)+\theta \gamma^{j} \Pi_{z j}^{i}
$$

The function $\mathrm{R}$ is the marginal return to a firm's own R\&D. Deriving this expression for each firm and setting it equal to one (the per unit cost of R\&D) generates a set of equations characterizing the firm's optimal R\&D policy given its competitor's $R \& D$ level. When solved simultaneously, these equations yield $M^{*}$.

In the context of symmetric equilibrium in duopoly, we can show that for any arbitrary parameter, $k$, that influences $\mathrm{M}^{*}$, the sign of $\frac{\partial M^{*}}{\partial k}$ equals the sign of $\mathrm{R}_{k}$.

Consider the first-order condition at the equilibrium values of $\mathbf{M}$ :

$$
\frac{\Pi^{i}\left(M^{i^{*}}, M^{j^{*}} \mid k\right)}{\partial M^{i}}=0
$$

Totally differentiating the first-order condition yields

$$
\begin{aligned}
& \frac{\partial^{2} \Pi^{i}}{\partial M^{i} \partial M^{i}} d M^{i}+\frac{\partial^{2} \Pi^{i}}{\partial M^{i} \partial M^{j}} d M^{j}=-\frac{\partial^{2} \Pi^{i}}{\partial M^{i} \partial k} d k \\
& \text { Let } a_{i} \equiv \frac{\partial^{2} \Pi^{i}}{\partial M^{i} \partial M^{i}}, b_{i}^{j} \equiv \frac{\partial^{2} \Pi^{i}}{\partial M^{i} \partial M^{j}} \text { and } \mu_{k}^{i} \equiv \frac{\partial^{2} \Pi^{i}}{\partial M^{i} \partial k} \text {. Using this notation, we can represent }
\end{aligned}
$$
in matrix form the total derivative for all firms:

$$
\left[\begin{array}{ll}
a_{1} & b_{1}^{2} \\
b_{2}^{1} & a_{2}
\end{array}\right]\left[\begin{array}{l}
d M^{1} \\
d M^{2}
\end{array}\right]=-\left[\begin{array}{l}
\mu_{k}^{1} d k \\
\mu_{k}^{2} d k
\end{array}\right]
$$

Assuming we have a symmetric equilibrium, we can rewrite this as

$$
\left[\begin{array}{ll}
a & b \\
b & a
\end{array}\right]\left[\begin{array}{l}
d M \\
d M
\end{array}\right]=-\left[\begin{array}{l}
\mu_{k} d k \\
\mu_{k} d k
\end{array}\right]
$$

This is simply two identical equations of the form

Therefore,

$$
(a+b) d M=-\mu_{k} d k
$$

$$
\frac{d M}{d k}=-\frac{\mu_{k}}{a+b}
$$

The myopic adjustment process, where each firm increases its output if it perceives positive marginal profit from this action, is defined by the differential equations,

$$
d^{i}=S^{i} \frac{\partial \Pi^{i}}{\partial M^{i}}
$$

where $S_{\mathrm{i}}>0$ are the adjustment speeds.

Linearizing around the equilibrium point $\mathrm{M}^{*}=\left(\mathrm{M}^{1 *}, \mathrm{M}^{2 *}\right)$, we have:

$$
\left[\begin{array}{l}
d^{1} \\
d^{2}
\end{array}\right]=\left[\begin{array}{ll}
S^{1} a & S^{1} b \\
S^{2} b & S^{2} a
\end{array}\right]\left[\begin{array}{c}
M^{1}-M^{1^{*}} \\
M^{2}-M^{2^{*}}
\end{array}\right]
$$

For stability, the coefficient matrix should have eigenvalues with negative real parts. This is so if 
and only if its trace is negative and determinant positive, i.e., $\mathrm{a}\left(\mathrm{S}^{1}+\mathrm{S}^{2}\right)<0, \mathrm{~S}^{1} \mathrm{~S}^{2}(\mathrm{a}+\mathrm{b})(\mathrm{a}-\mathrm{b})>0$.

If this is to hold independently of adjustment speeds, we need $\mathrm{a}<0,(\mathrm{a}+\mathrm{b})(\mathrm{a}-\mathrm{b})>0$

These will be referred to as the stability conditions. These conditions imply that $a+b<0$.

Therefore, the sign of $\frac{d M}{d k}$ is the same as the signs of both $\mu_{\mathrm{k}}$ and $\mathrm{R}_{k}$. To simplify the notation of our results, we only present the analogues of $\mathrm{R}_{k}$, including $\mathrm{R}_{\beta}$ and $\mathrm{R}_{\theta}$ to establish the signs of $\frac{\partial M^{*}}{\partial \beta}$ and $\frac{\partial M^{*}}{\partial \theta}$. To provide an intuitive sense of the basic forces at work, we simplify the analysis by considering only the first-order effect of knowledge on firm profit and assume the second-order condition to be constant. Given this assumption, we can show the sign of $\frac{\partial^{2} M^{*}}{\partial \beta \partial \theta}$ is identical to the sign of $\mathrm{R}_{\beta \theta}$.

Deriving $R_{\beta}$ and constraining the second-order terms of $\Pi^{\mathrm{i}}$ with respect to knowledge to be zero allow us to characterize the effect of $\beta$ on R\&D spending as

$$
\operatorname{sign}\left(\frac{\partial M^{*}}{\partial \beta}\right)=\operatorname{sign}\left(\Pi_{z i}^{i} \gamma_{M \beta} \theta M+\theta \frac{\partial \gamma}{\partial \beta} \Pi_{z j}^{i}\right)
$$

Based on the assumptions explained above, the sign is positive.

Next, we examine the sign of $\frac{\partial M^{*}}{\partial \theta}$. Again, deriving $\mathrm{R}_{\theta}$ and constraining the second-order terms of $\Pi^{\mathrm{i}}$ with respect to knowledge to be zero allow us to characterize the effect of $\theta$ on R\&D spending as

$$
\operatorname{sign}\left(\frac{\partial M^{*}}{\partial \theta}\right)=\operatorname{sign}\left(\Pi_{z i}^{i} \gamma_{M} M+\gamma \Pi_{z j}^{i}\right)
$$

This sign is ambiguous. This ambiguity is due to two offsetting effects: the benefit to the firm of increasing its absorptive capacity, represented by $\Pi_{z i}^{i} \gamma_{M} M$, and the loss associated with the diminished appropriability of rents as spillovers increase, represented by $\gamma \Pi_{z j}^{i}$. However, this equation suggests that the positive impact of $\theta$ is typically greater for larger values of $\beta$ (the impact of own $R \& D$ on absorptive capacity). To evaluate this effect, it is necessary to evaluate the cross-partial derivative, $\frac{\partial^{2} M^{*}}{\partial \beta \partial \theta}$, by deriving $\mathrm{R}_{\beta \theta}$. If we focus on first-order effects of $\mathrm{z}$ on profit and assume that $\gamma_{\mathrm{MM}}=0$, then we can show that $\mathrm{R}_{\beta \theta}$ is positive. Under these conditions,

$$
\operatorname{sign}\left(\frac{\partial^{2} M^{*}}{\partial \beta \partial \theta}\right)=\operatorname{sign}\left(M_{j} \gamma_{M \beta} \Pi_{z i}^{i}+\gamma_{\beta} \Pi_{z j}^{i}+\gamma_{M} \frac{\partial M^{*}}{\partial \beta}\left(\Pi_{z i}^{i}+\Pi_{z j}^{i}\right)\right)
$$

Based on the assumptions explained above, this sign is positive. Therefore, when $\beta$ is large or companies possess more complementary knowledge, it is more likely that $\frac{\partial M^{*}}{\partial \theta}$ is positive, from claim 1 that $\theta^{\mathrm{C}^{*}}(\beta)$ $>\theta^{\mathrm{NC}^{*}}(\beta)$ with large $\beta$ implies $\mathrm{M}^{\mathrm{C}^{*}}(\beta)>\mathbf{M}^{\mathrm{NC}}(\beta)$. Thus, a cooperatively determined knowledge sharing rate increases the private $R \& D$ level. 
Appendix 3. Numerical example

$\mathrm{c}^{\mathrm{i}}=\mathrm{e}^{-\mathrm{zi}}$

$\gamma^{\mathrm{i}}=\beta \mathrm{M}^{\mathrm{i}}+1-\beta$

$\mathrm{D}^{-1}=4-\left(\mathrm{q}_{\mathrm{i}}+\mathrm{q}_{\mathrm{j}}\right)$

$s\left(\theta^{i}\right)=\left\{1 / 10 \tan \pi\left(\theta^{i}-1 / 2\right)\right\}^{2}$

Figure 1. Equilibrium knowledge sharing rate (spillover rate)

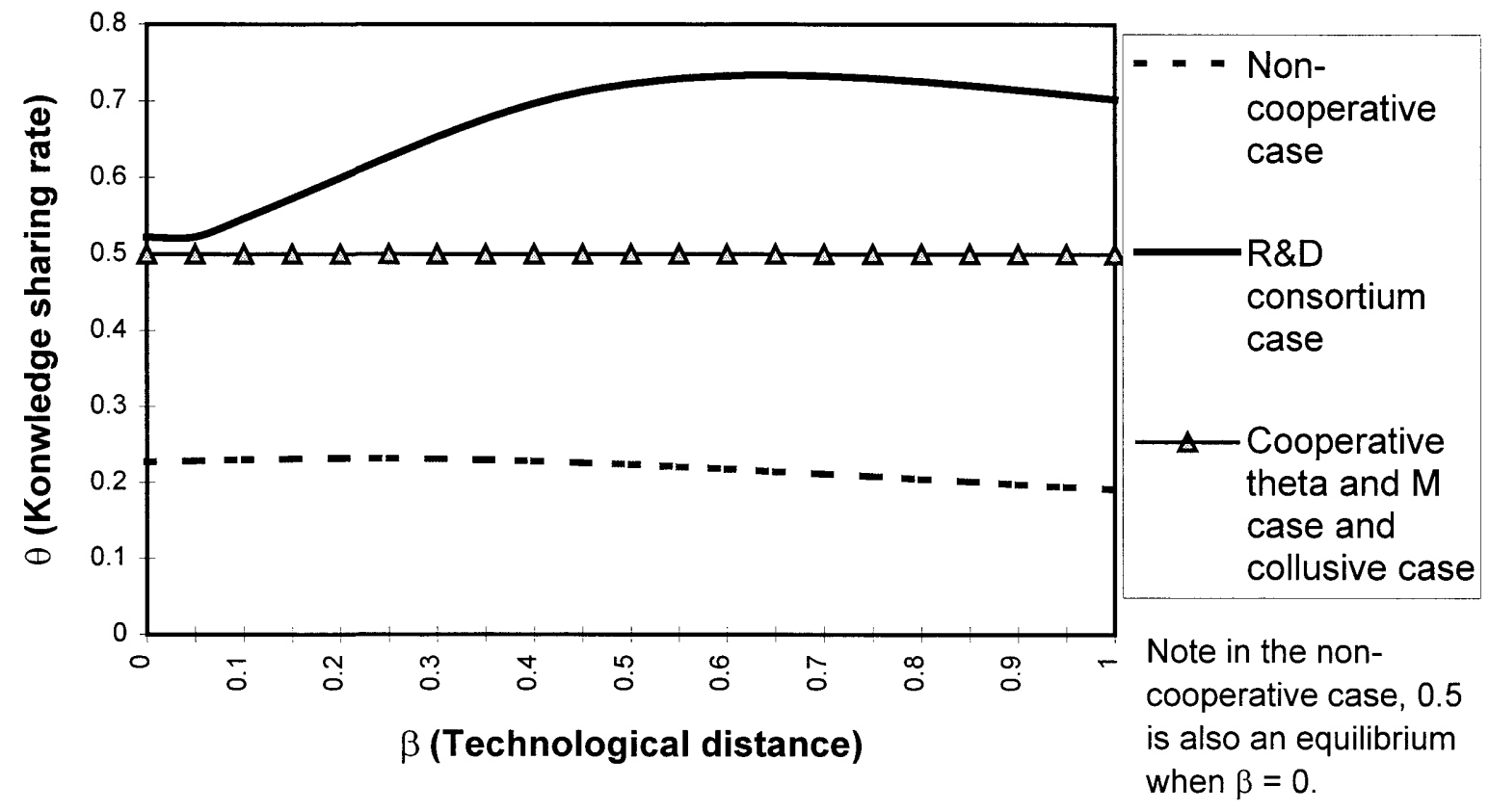

Figure 2. R\&D expenditure
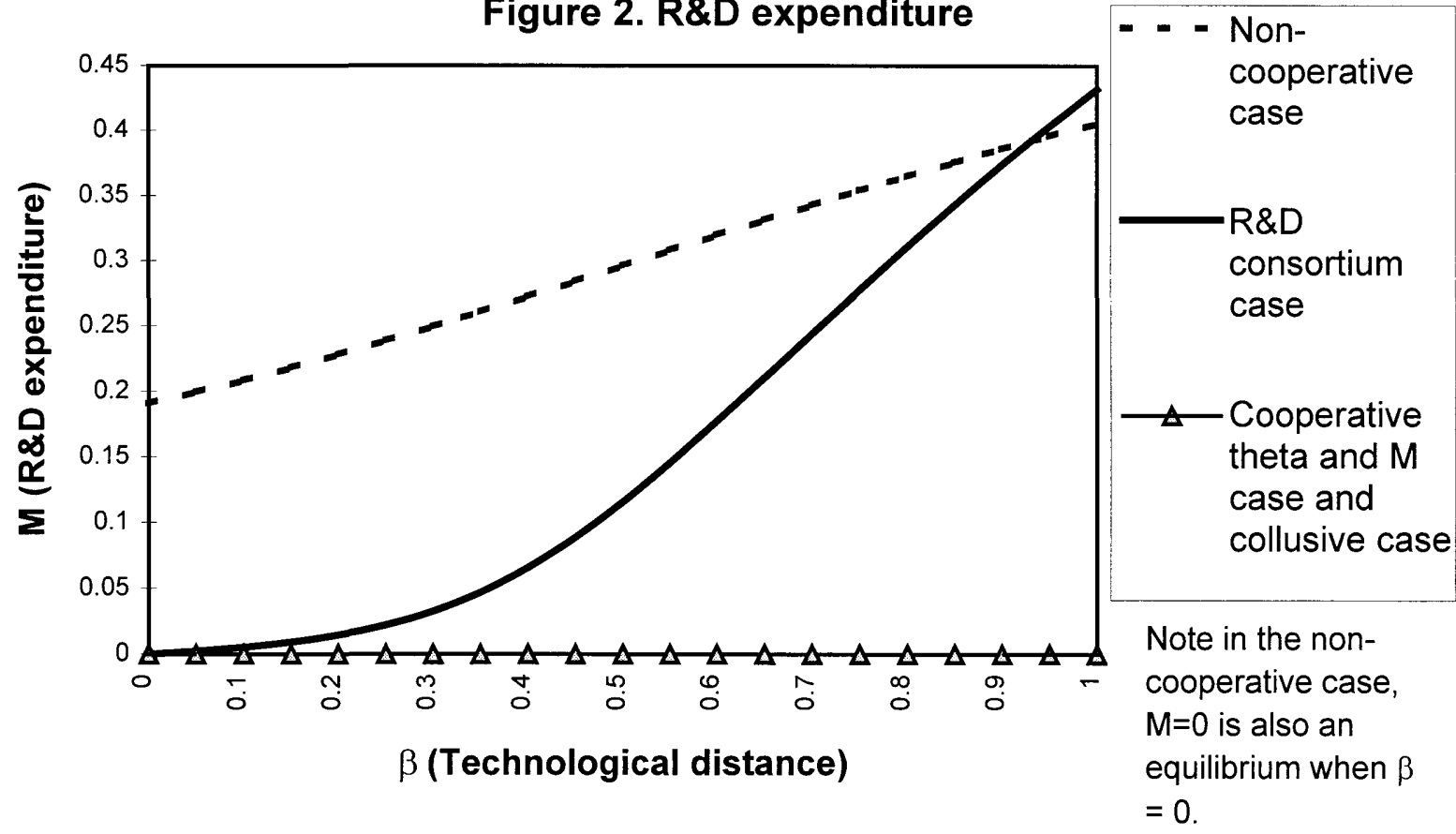
theta and $M$ case and collusive case

Note in the noncooperative case, $\mathrm{M}=0$ is also an equilibrium when $\beta$ $=0$. 
Appendix 3. (cont.)

Figure 3. Marginal production cost

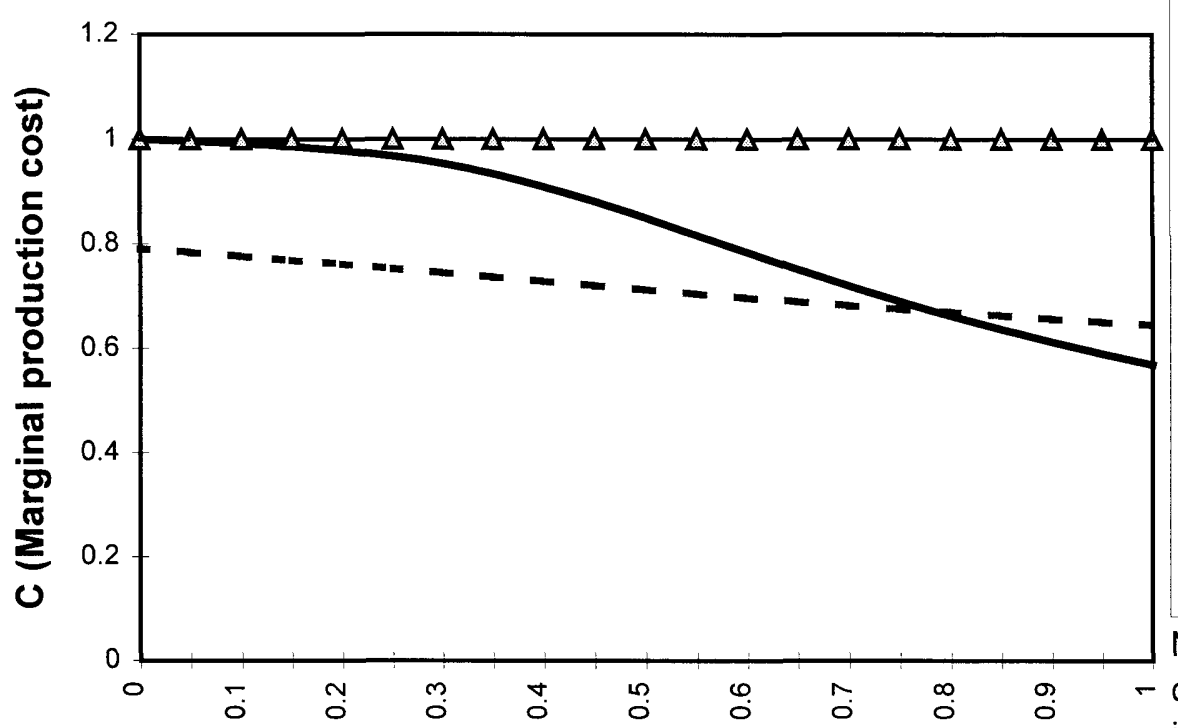

$\beta$ (Technological distance)
- - Noncooperative case

R\&D consortium case

$\triangle$ Cooperative theta and $M$ case and collusive case

Note in the noncooperative case, $c=1$ is also an equilibrium when $\beta=0$.

Figure 4. Profit

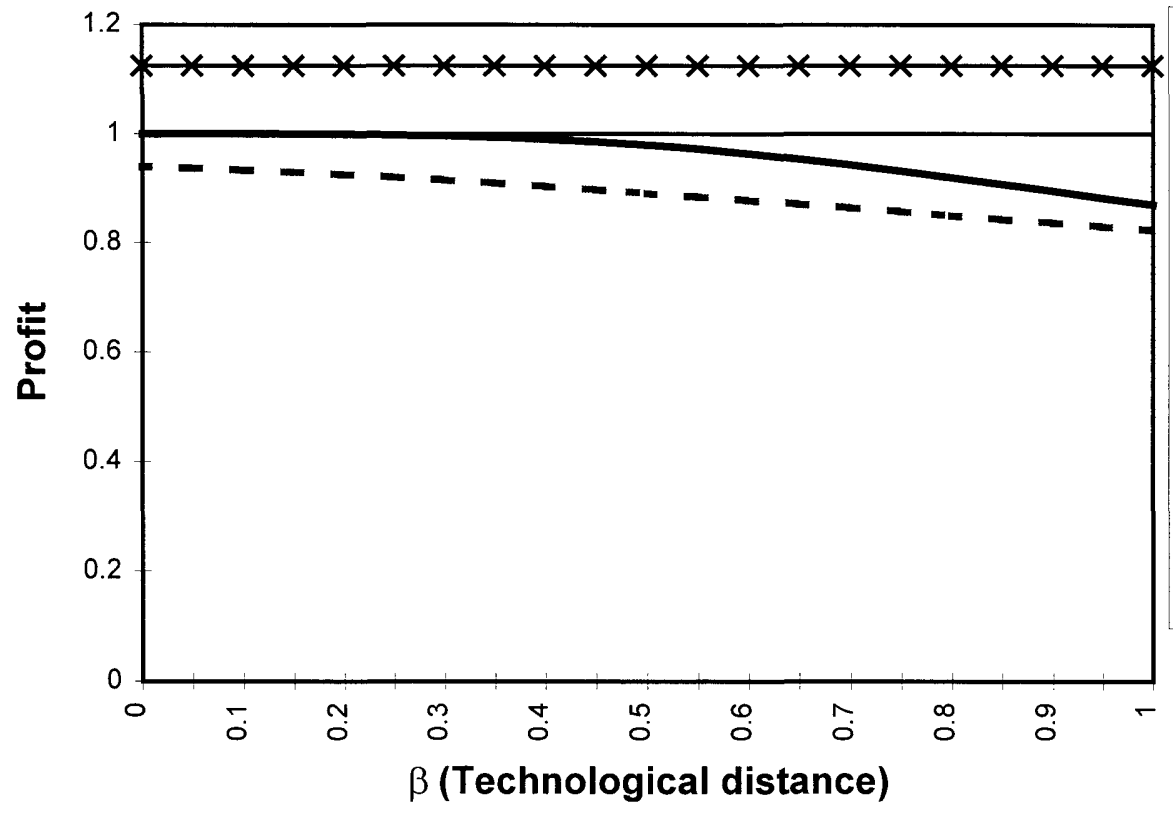

- - Noncooperative case

$R \& D$ consortium case Cooperative theta and $M$ case

$\rightarrow$ Collusive case

Note in the noncooperative case, 1 is also an equilibrium when $\beta=0$. 
Appendix 3. (cont.)

Figure 5. Welfare

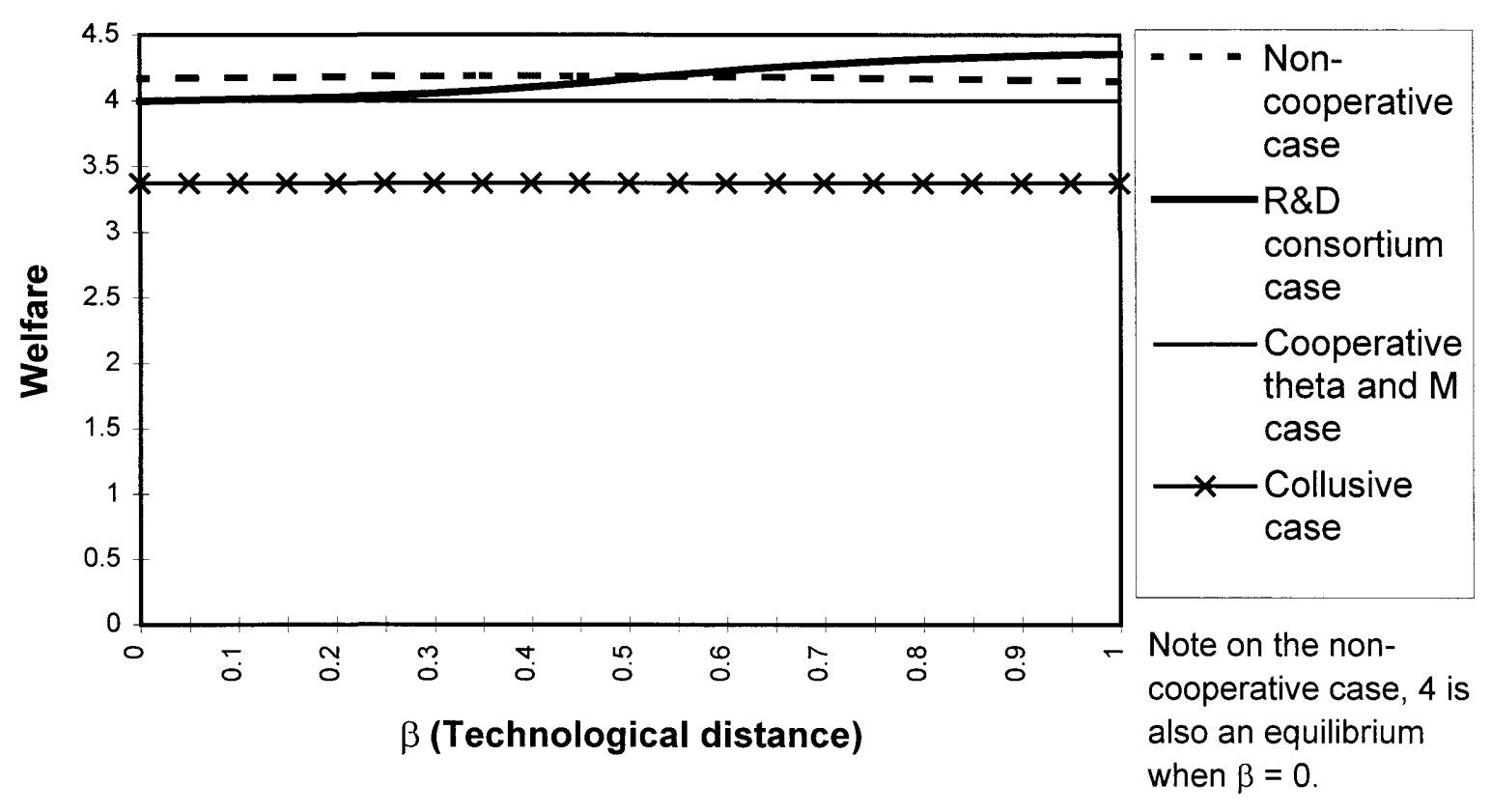




\section{Appendix 4. Diversity measure: diversity of participating firms' main businesses}

\section{Identification of firms' main businesses}

In order to obtain an objective measure to identify the primary industry of participating firms, we used Kaisha Kigyo Meikan (Company Almanac) edited by the Statistics Bureau of the Management and Coordination Agency, Japan. This source is a list of companies that are covered by the Census of Establishments, an official census by the Japanese Government. In the Company Almanac, each company reports the SIC three-digit level industry codes to which its establishments belong. We used the SIC code the firm reported as the primary industry for its headquarters to identify each company's main business. When the firm reports the function of headquarters (such as wholesaling) instead of the industry, we used the industry to which the largest factory of the firm was assigned as the primary industry. Many companies have been assigned to different industries at different times as they change their primary industries. We used the SIC code of a firm at the time the firm joined the project. We used 1963 data for the analysis of the data in the 1960s and earlier, 1972 data for the 1970s, and 1986 data for the 1980s, due to the availability of the source.

\section{Calculation of diversity measures}

Montgomery product count measures

$$
\text { diversity }=1-\frac{\sum m_{j}{ }^{2}}{\left(\sum_{j} m_{j}\right)^{2}}
$$

$\mathrm{m}_{\mathrm{j}}=$ the share of firms that are in industry segment $\mathrm{j}$; where $\mathrm{j}$ is measured at the 3-digit SIC code.

Palepu entropy measures

Total diversity

$$
\mathrm{DT}=\sum_{i=1}^{n} P_{i} \ln \left(1 / P_{i}\right)
$$

$\mathrm{P}_{\mathrm{i}}=$ the share of firms in the ith industry at the 3-digit SIC level

$\mathrm{n}=$ the number of SIC industries at the 3-digit level

For the calculation, it is assumed that each firm has an equal share in an R\&D consortium. 


\section{Appendix 5. Diversity measure: technological diversity}

The framework for this calculation was pioneered by Jaffe (1986) and modified by Branstetter (1996a,b) and Branstetter and Sakakibara (1998).

The typical firm conducts R\&D in a number of technological fields simultaneously. We could obtain a measure of a firm's location in "technology space" by measuring the distribution of its R\&D effort across various technological fields. Let a firm's R\&D program be described by the vector F, where

$$
F_{i}=\left(f_{1} \ldots f_{k}\right)
$$

and each of the $k$ elements of $F$ represent the firm's research resources and expertise in the $k$ th technological area. We can infer from the number of patents granted to a firm in different technological areas the distribution of a firm's R\&D investment and technological expertise across different technical fields. In other words, by counting the number of patents held by a firm in a narrowly defined technological field, we can obtain a quantitative measure of the firm's level of technological expertise in that field. Fifty distinct technological fields are used for the calculation.

We can measure the "technological proximity" between two firms by measuring the degree of similarity in their patent portfolios. Firms working on the same technologies will tend to patent in the same technological areas. We can state this more precisely: the "distance" in "technology space" between two firms $i$ and $j$ can be approximated by $T_{i j}$ where $T_{i j}$ is the uncentered correlation coefficient of the $F$ vectors of the two firms, or

$$
T_{i j}=\frac{F_{i} F_{j}^{\prime}}{\left[\left(F_{i} F_{i}^{\prime}\right)\left(F_{j} F_{j}^{\prime}\right)\right]^{1 / 2}}
$$

We calculated $\mathrm{F}$ vectors from the data of U.S. patents granted to Japanese consortia participants. When Japanese firms file patent applications to the U.S. patent office, they tend to be selective because of relatively higher U.S. patent agent fees and translation fees, and so they tend to file only applications for promising inventions. The U.S. patent data, therefore, can be viewed as a quality-adjusted measure of technological expertise for Japanese firms, and so the use of U.S. patent data has an advantage over the use of Japanese patent data. Operationally, U.S. patent data is less costly to obtain than Japanese patent data.

$T_{i j}$ can be calculated for each firm pair in a given consortium. For each consortia, we can calculate the average technological proximity of participants in consortium $\mathrm{m}, T P_{m}$, as

$$
T P_{m}=\text { the sum of } T_{i j} \text { for all pairs / the number of pairs: } \frac{1}{2} n(n-1)
$$

where $\mathrm{n}$ is a number of participants in consortium $\mathrm{m}$. Note $0 \leq T P_{m} \leq 1$, and the larger the number, the closer firms are to each other in the technology field. This measure is calculated from 1980 and 1996 and averaged. In order to make this measure comparable to other diversity measures, we calculate consortium m's technological diversity measure $T D_{m}$ as

$$
T D_{m}=1-T P_{m}
$$

which is an average technological distance among participants in consortium $\mathrm{m}$. The larger the number, the more diverse the participating firms in a consortium in the technology field, with $0 \leq T D_{m}$ $\leq 1$. 


\section{References}

Arrow, K.J. "Economic Welfare and the Allocation of Resources for Invention." In R.R. Nelson ed., The Rate and Direction of Inventive Activity: Economic and Social Factors. Princeton University Press, Princeton, 1962, pp. 609 - 626.

d'Aspremont, C. and Jacquemin, A. "Cooperative and Noncooperative R\&D in Duopoly with Spillovers.” American Economic Review, Vol. 78 (1988), pp. 1133 - 1137.

Branstetter, L. "Are Knowledge Spillovers Intranational or International in Scope: Microeconometric Evidence from the United States and Japan." NBER Working Paper (1996a).

Branstetter, L. Innovation, Knowledge Spillovers, and Dynamic Comparative Advantage: Evidence from Japan and the United States. Ph.D. Thesis, Harvard University, 1996b.

Branstetter, L. and Sakakibara, M. "Japanese Research Consortia: A Microeconometric Analysis of Industrial Policy.” Journal of Industrial Economics, Vol. 46 (1998), pp. 207 - 233.

Choi, J.P. Essays in the Theory of Dynamic R\&D Competition. Ph.D. Thesis, Harvard University, 1990.

Cohen, W.M. and Levinthal, D.A. "Innovation and Learning: The Two Faces of R\&D." Economic Journal, Vol. 99 (1989), pp. 569 - 610.

Dixit, A. "Comparative Statics for Oligopoly." International Economic Review, Vol 27 (1986), pp 107 122.

Dunning, J.H. and Robson, P. eds. Multinationals and the European Community. Basil Blackwell, New York, 1988.

Fransman, M. The Market and Beyond: Cooperation and Competition in Information Technology Development in the Japanese System. Cambridge University Press, Cambridge, U.K., 1990.

Griliches, Z. "The Search for R\&D Spillovers." Scandinavian Journal of Economics, Vol. 94 (1992), pp. $29-47$.

Griliches, Z. and Mairesse, J. "R\&D and Productivity Growth: Comparing Japanese and U.S. Manufacturing Firms." In C.R. Hulten ed., Productivity Growth in Japan and the United States. University of Chicago Press, Chicago, 1990, pp. 317 - 348.

Hamel, G. "Competition for Competence and Inter-Partner Learning within International Strategic Alliances." Strategic Management Journal, Vol. 12 (1991), pp. 83 - 103.

Irwin, D. and Klenow, P. "High Tech R\&D Subsidies: The Effects of Sematech." Journal of International Economics, Vol. 40 (1996), pp. 323 - 344.

Jaffe, A.B. "Technological Opportunity and Spillovers of R\&D: Evidence from Firms' Patents, Profits, and Market Value." American Economic Review, Vol. 76 (1986), pp. 984 -1001.

Kamien, M.I., Muller, E., and Zang, I. "Research Joint Ventures and R\&D Cartels." American 
Economic Review, Vol. 82 (1992), pp. 1293 - 1306.

Katz, M.L. “An Analysis of Cooperative Research and Development." RAND Journal of Economics, Vol. 17 (1986), pp. 527 - 543.

Katz, M.L. and Ordover, J.A. "R\&D cooperation and competition." Brookings Papers on Economic Activity: Microeconomics (1990), pp. 137 - 203.

Kodama, F. "Direct and Indirect Channels for Transforming Scientific Knowledge into Technical Innovations." In B. Bartocha and S. Okamura, eds., Transforming Scientific Ideas into Innovations: Science Policy in the United States and Japan. Japan Society for the Promotion of Science, Tokyo, 1985.

Kodama, F. “Technology Fusion and the New R\&D.” Harvard Business Review, Vol. 70 (1992), pp. 70 78.

Kogut, B. "Joint Ventures: Theoretical and Empirical Perspectives." Strategic Management Journal, Vol. 9 (1988), pp. 319 - 332.

Kole, S.R. and Lehn, K. "Deregulation and the Adaptation of Governance Structure: The Case of the U.S. Airline Industry." Working paper, University of Rochester, 1996.

Levin, R.C., Klevorick, A.K., Nelson, R.R., and Winter S.G. "Appropriating the Returns from Industrial Research and Development." Brookings Papers on Economic Activity, Vol. 3 (1987), pp. $783-820$.

Levin, R.C. and Reiss, P.C. "Cost-reducing and Demand-creating R\&D with Spillovers." RAND Journal of Economics, Vol. 19 (1988), pp. 538 - 556.

Link, A. N., Teece, D.J., and Finan, W. F. "Estimating the Benefits from Collaboration: The Case of Sematech." Review of Industrial Organization, Vol. 11 (1996), pp. 737 - 751.

Montgomery, C.A. "The Measurement of Firm Diversification: Some New Empirical Evidence." Academy of Management Journal, Vol. 25 (1982), pp. 299 - 307.

Motta, M. "Cooperative R\&D and Vertical Product Differentiation." International Journal of Industrial Organization, Vol. 10 (1992), pp. 643 - 661.

Murphy, W.J. R\&D Cooperation among Marketplace Competitors. Quorum Books, Westpoint, Connecticut, 1991.

Nelson, R.R. "The Simple Economics of Basic Research.” Journal of Political Economy, Vol. 67 (1959), pp. $297-306$.

OECD. Policy Evaluation in Innovation and Technology: Towards Best Practices. OECD, Paris, 1997.

Okimoto, D.I. Between MITI and the Market: Japanese Industrial Policy for High Technology. Stanford University Press, Stanford, 1989. 
Ouchi, W.G. and Bolton, M.K. "The Logic of Joint Research and Development." California Management Review, Vol. 30 (1988), pp. 9 - 33.

Palepu, K. "Diversification Strategy, Profit Performance and the Entropy Measure." Strategic Management Journal, Vol. 6 (1985), pp. 239 - 255.

Polanyi, M. Personal Knowledge: Towards a Post-critical Philosophy. University of Chicago Press, Chicago, 1958.

Poyago-Thetoky, J. "Equilibrium and Optimal Size of a Research Joint Venture in an Oligopoly with Spillovers." Journal of Industrial Economics, Vol. 43 (1995), pp. 209 - 226.

Prahalad, C.K. and Hamel, G. "The Core Competence and the Corporation." Harvard Business Review, Vol. 68 (1990), pp. 71 - 91.

Sakakibara, M. "Heterogeneity of Firm Capabilities and Cooperative Research and Development: An Empirical Examination of Motives." Strategic Management Journal, Vol. 18 (1997a), pp. 143 164.

Sakakibara, M. "Evaluating Government-sponsored R\&D Consortia in Japan: Who Benefits and How?" Research Policy, Vol. 26 (1997b), pp. 447 - 473.

Salant, S.W. and Shaffer, G. "Optimal Asymmetric Strategies in Research Joint Ventures." International Journal of Industrial Organization, Vol. 16 (1998), pp. 195 - 208.

Spence, M. "Cost Reduction, Competition, and Industry Performance." Econometrica, Vol. 52 (1984), pp. $101-121$.

Steurs, G. "Inter-industry R\&D Spillovers: What Difference Do They Make?" International Journal of Industrial Organization, Vol. 13 (1995), pp. 249 - 276.

Suzumura, K. "Cooperative and Noncooperative R\&D in an Oligopoly with Spillovers." American Economic Review, Vol. 82 (1992), pp. 1307 - 1320.

Vonortas, N.S. "Inter-firm Cooperation with Imperfectly Appropriable Research." International Journal of Industrial Organization, Vol. 12 (1994), pp. 413 - 435.

White, H. "A Heteroskedasticity-Consistent Covariance Matrix and a Direct Test for Heteroskedasticity." Econometrica, Vol. 48 (1980), pp. 817 - 838.

Ziss, S. "Strategic R\&D with Spillovers, Collusion and Welfare." Journal of Industrial Economics, Vol. 42 (1994), pp. 375 - 393. 